\title{
Article \\ Increasing the Reliability of an Electrical Power System in a Big European Hospital through the Petri Nets and Fuzzy Inference System Mamdani Modelling
}

\author{
Constâncio António Pinto ${ }^{1} \mathbb{D}$, José Torres Farinha ${ }^{1,2, * \mathbb{D}}$, Sarbjeet $\operatorname{Singh}^{3}$ and Hugo Raposo ${ }^{1,2} \mathbb{D}$ \\ 1 CEMMPRE, Department of Mechanical Engineering, University of Coimbra, 3030-788 Coimbra, Portugal; \\ watumaubere@gmail.com (C.A.P.); hugo.raposo@isec.pt (H.R.) \\ 2 Instituto Superior de Engenharia de Coimbra/Instituto Politécnico de Coimbra (ISEC/IPC), \\ 3030-199 Coimbra, Portugal \\ 3 Department of Civil, Environmental and Natural Resources Engineering, Lulea University of Technology, \\ 97187 Luleå, Sweden; sarbjeet.singh@1tu.se \\ * Correspondence: torres.farinha@dem.uc.pt
}

Citation: Pinto, C.A.; Farinha, J.T.; Singh, S.; Raposo, H. Increasing the Reliability of an Electrical Power System in a Big European Hospital through the Petri Nets and Fuzzy Inference System Mamdani

Modelling. Appl. Sci. 2021, 11, 2604. https://doi.org/10.3390/app11062604

Academic Editor: Marlene Amorim

Received: 20 February 2021

Accepted: 9 March 2021

Published: 15 March 2021

Publisher's Note: MDPI stays neutral with regard to jurisdictional claims in published maps and institutional affiliations.

Copyright: (c) 2021 by the authors. Licensee MDPI, Basel, Switzerland. This article is an open access article distributed under the terms and conditions of the Creative Commons Attribution (CC BY) license (https:/ / creativecommons.org/licenses/by/ $4.0 /)$.

\begin{abstract}
The big hospitals' electricity supply system's reliability is discussed in this article through Petri nets and Fuzzy Inference System (FIS). To simulate and analyse an electric power system, the FIS Mamdani in MATLAB is implemented. The advantage of FIS is that it uses human experience to provide a faster solution than conventional techniques. The elements involved are the Main Electrical Power, the Generator sets, the Automatic Transfer Switches (ATS), and the Uninterrupted Power Supply (UPS), which are analysed to characterize the system behaviour. To evaluate the system and identified the lower reliability modules being proposed, a new reliable design model through the Petri Nets and Fuzzy Inference System approach. The resulting approach contributes to increasing the reliability of complex electrical systems, aiming to reduce their faults and increase their availability.
\end{abstract}

Keywords: maintenance reliability; availability; Petri nets; fuzzy inference system; dynamic modelling

\section{Introduction}

The electric power system plays a strategic function in a big European hospital. Therefore, the managers have an extreme interest in maintaining the electricity system working correctly. If a failure happens, it will cause dangerous problems for the hospital's activities and people in its operational context. Thus, the power source system must be designed to be very reliable to maintain the system working with maximum availability. Because of the specificity of this type of asset, its maintenance and reliability are strategic. This paper aims to improve this system's reliability by using the fuzzy inference system and Petri nets to simulate and improve the existing system with a new and more reliable design, using MATLAB as the simulation tool.

The structure of the paper is the following: Section 1 presents the introduction; Section 2 presents state of the art-the maintenance concepts, the maintenance activity in a hospital, the reliability and availability of maintenance systems, the Petri nets system, and the fuzzy Petri nets and fuzzy logic system; Section 3 describes the electrical power system of a big European hospital - the characterization of the hospital, the hospital electrical system modelling using block diagrams, the group of generators, the automatic transfer switch (ATS), and the uninterrupted power supply (UPS); Section 4 presents the modelling of the hospital's electrical system using the Petri nets software simulator HiPS description, the modelling of the hospital's electrical system using Petri nets, the explanation of the hospital electrical system, and the modelling and analysis using fuzzy logic; Section 5 presents the conclusions, including proposals for future developments. 


\section{State of the Art}

\subsection{The Maintenance Concept}

Maintenance is an essential factor for the sustainability of the asset's operating functions and, by consequence, its availability and reliability. Maintenance is also a way to mitigate the damages that will occur in assets; therefore, the people in charge must be competent in their professional fields. This paper is based on existing norms and relevant research papers relating to maintenance aiming to support new ideas that may be relevant for further improvement, namely based on the following quotations. The American Hospital Association (1980) mentions that "proper maintenance of the power system is essential to its safety and reliability. The designer may incorporate certain features into the system to make maintenance safer and more comfortable and to make it possible to perform routine maintenance and inspection without dropping essential hospital load" [1]. Anderson and Neri (1990) reported that "support deals with the specific procedures, tasks, instructions, personnel qualification, equipment needed to satisfy the system maintainability requirement within an actual environment use" [2]. According to the Department of the Army, maintenance is defined as "those operations and actions that directly retain the appropriate activity of an item or renewing that operation when it is disturbed by failure or some other anomaly-within the context of RCM, the necessary process of an object means that it can perform its intended function" [3]. Farinha (2011) also referred to the norm EN 13306:2010 that defines maintenance as the "combination of all technical, administrative and managerial actions during the life cycle of an item intended to retain it in or restore it to, a state in which it can perform the required function" [4]. Gulati (2009) stated that "Maintenance is concerned with keeping an asset in right working conditions, so that the asset may be used to its full productive capacity. The maintenance function includes both upkeep and repairs" [5]. Moubray (1997) stated that "the role of Maintenance is to ensure that physical assets continue to do what their users want to do" [6]. Wang (2012) said that "Maintenance is a function that operates in parallel to production and can have a significant impact on the capacity of the production and quality of the products produced, and therefore, it deserves continuous improvement" [7]. It can be considered that maintenance is a management tool to prevent failures in the physical assets, using both planned and non-planned interventions to maintain their useful lives, in charge of the maintenance engineers.

\subsection{The Electrical Maintenance Activity in Hospitals}

This paper discusses the maintenance and modelling of the electricity system that supplies electricity to a big European hospital, as shown in Figures 7 and 8. To analyse the maintenance of the electricity system, the norms and papers of other researchers relating to hospitals were used to support new ideas that are relevant for further improvement based on the following quotations. AHA (1980) states that "the engineering and maintenance department charged with the responsibility for ensuring the safe, cost-effective operation and maintenance of hospital facilities and expensive equipment" [1]. Farinha (2001) mentioned that "another way of analysing the useful life was proposed by (AHA, 1996), based on the knowledge of type parameters of most hospital equipment, which allows establishing the maximum limit of maintenance expenses from the ones it is more economical to replace the equipment than to repair it" [4]. Mwanza and Mbohwa (2015) concluded that "the maintenance practices in three hospitals are not effective. The conclusion based on the lack of work order system to capture all work to manage labour, no skill training programs and poor spare inventory and purchasing system" [8]. The IEEE C2: National Electrical Safety Code (2007) mentions that "the purpose of this standard covers basic provisions for safeguarding of people from hazards arising from the installation, action, or maintenance of (1) conductors and equipment in electric supply stations, and (2) overhead and underground electric supply and communication lines" [9]. Christiansen (2015) mentioned that "this paper presents a model approach based on over $33,500 \mathrm{~h}$ of measurements within a modern University Medical Centre of Hamburg/Germany to assess the time-dependent course 
as well as the weekly sum of the demand for electrical energy due to medical laboratory plug loads" [10]. According to AHA (1980), "safety requires adequate provision for the protection of life, property, and continuity of hospital services. The protection of human life is paramount" [1]. BenSaleh et al. (2010) mentioned that "as there are more and more automated hospitals, the greater protection against the lack of energy. Hospital systems are increasingly dependent on technology, well-designed emergency energy systems, and the ability to adapt to the changing environments" [11]. Jamshidi (2014) mentioned that "RiskBased Maintenance (RBM) is composed of two main components: (1) A comprehensive framework for prioritization of the critical medical devices; (2) A method for selecting the best maintenance strategy for each device. Risk-based prioritization of medical devices is valuable to health organizations in the sequencing of maintenance activities and budget allocation for maintenance activities" [12]. The World Health Organization (WHO) and Pan American Health Organization (2015) mention that "promoting 'the aims of 'hospitals safe from disasters' by ensuring that all new hospitals aware about the safety that will provide them to function in disaster situations and implement mitigation measures to reinforce existing health facilities, particularly those providing primary health care" [13]. Abdul et al. (2015) presented a "study on equipment inspection and shutdown at optimized, risk-based maintenance intervals for a processing facility unit, considering the human errors that introduced during these activities" [14].

\subsection{Maintenance, Reliability, and Availability}

Maintenance, reliability, and availability are essential tools to prevent failures, damages, and delays in the production processes and services in terms of time, costs, and systems' performance. The quality management effort for internal and external customer's satisfaction, guided by the international norms and world conventions, takes advantage of the research relating to hospital physical assets to support new ideas relevant to further improvement like the following authors described. Ali et al. (2019) stated that "to develop a safety and profitable process, uncertainty quantification is necessary for a reliability, availability, and maintainability (RAM) analysis. The uncertainties of $3 \%$ in each key decision variable are propagated, bringing the system into an unreliable/risk region. This approach reduces about $90 \%$ of the total computational time when compared with the conventional simulation approaches required for a complex first principle-based model" [15]. Arias et al. (2019) stated that the "reliability model is based on the information available in the maintenance system-driven framework using both classical and Bayesian methodologies. It illustrates the ageing process and the necessary data for the creation of the model. This model can be demonstrated and analysed with an important factor; it represents the flexibility to build the reliability expected during the maintenance strategy-making and the knowledge of the equipment" [16]. Calixto (2016) stated that "RAM analysis is the basis for complex system performance analysis. To demonstrate such a methodology, the RAM analysis steps, such as scope definition, lifetime data analysis, modelling, simulation, critical analysis, sensitivity analysis, and conclusions, will be discussed" [17]. Çekyay and Özekici (2015) stated that "system reliability, mean time to failure, and steady-state availability, are functions of the component failure rates. The primary objective is providing explicit expressions for these performance measures and obtaining various characterizations on their mathematical structures" [18]. Corvaro et al. (2017) stated that "the complex of RAM factors constitutes a strategic approach for integrating reliability, availability, and maintainability, by using methods, tools and engineering techniques (Mean Time to Failure, Equipment Down Time and System Availability values) to identify and quantify equipment and system failures that prevent the achievement of productive objectives" [19]. Ebeling (2010) suggested that "Reliability is defined to be the probability that a component or system will perform a required function for a given period when used under state operating conditions" and that "Maintainability is defined to be a probability that a failed component or system will be restored or repaired to a specified condition within a period when maintenance is performed following prescribed procedures 
and Availability is defined as the probability that a component or system is performing its required function at a given point in time when used under state operation condition" [20]. Feng et al. (2011) stated that "many problems have existed in synthesis of design of Reliability, Maintainability, Supportability (RMS) and performance; such as RMS design activities are numerous and optional, variable feedback branches can satisfy same RMS requirement, some iteration among RMS and Performance activities is necessary, and many uncertainties exist in the design process" [21]. Hameed et al. (2011) stated that "the need, method, benefits, and possible areas of application for the proposed RAM database have been identified. Both the technical and managerial challenges were outlined, which could be encountered during this database's realisation. The structure for the database is suggested keeping in view the implementation of RAM concepts quickly and efficiently" [22]. Sikos and Klemeš (2010) stated that "the proposed methodology focuses on HEN maintenance through the influence of availability and reliability rather than the optimization of cleaning schedules only. It has been shown that the failure analysis is capable of predicting heat exchanger bundle replacement times, leading to significant savings" [23]. Song and Wang (2013) presented "a comprehensive review of reliability assessment and improvement of power electronic systems from three levels: (1) metrics and methodologies of reliability assessment of existing system; (2) reliability improvement of an existing system using algorithmic solutions without change of the hardware; and (3) reliability-oriented design solutions that are based on the fault-tolerant operation of the overall systems" [24]. Sutton (2015) stated that "Reliability, Availability, and Maintainability (RAM) programs are an integral part of any risk management system. RAM techniques possess many similarities to those that are used for safety" [25]. Wang et al. (2013) stated that "failure of a component in Building Cooling, Heating and Power (BCHP) system may fail a sub-system or the whole system. The reliability and availability analysis of the BCHP system is helpful to the designer to decide the redundancy in case of equipment failure" [26]. Zio et al. (2019) considered "reliability engineering in the modern civil aviation industry, and the related engineering activities and methods. They consider reliability in a broad sense, referring to other system characteristics that are related to it, like availability, maintainability, safety and durability" [27]. Shen et al. (2019) mentioned that "to describe the system performance, system availabilities including instantaneous availability and limiting average availability, and some time distributions of interest are important indexes. Then, the problem of optimal maintenance policy is formulated by considering constraints of availability and operating times" [28]. Do et al. (2015) proposed and showed "how to optimize a dynamic maintenance decision rule on a rolling horizon? The heuristic optimization scheme for the maintenance decision is developed by implementing two optimization algorithms (genetic algorithm and MULTI FIT) to find optimal maintenance planning under both availability and limited repairmen constraints" [29].

From the dynamics of various opinions regarding reliability, availability, and maintenance, it is essential to pay close attention to these variables to ensure the production industry's successor service satisfies customers.

\subsection{Petri Nets Systems}

This paper corresponds to the evolution of the authors' research. Because of this, some of the next sections are strongly supported in Reference [30].

A Petri net may be defined by 5 -tuples $\mathrm{N}=(\mathrm{P}, \mathrm{T}, 1,0, \mathrm{Mo})$, where

(1) $\mathrm{P}=\{\mathrm{P} 1, \mathrm{P} 2, \ldots, \mathrm{Pm}\}$ is a limited set of places;

(2) $\mathrm{T}=\{\mathrm{t} 1, \mathrm{t} 2, \ldots, \mathrm{tn}\}$ is a limited set of transitions, $\mathrm{P} \mathrm{U} \mathrm{T} \neq \varnothing$, and $\mathrm{P} \cap \mathrm{T}=\varnothing$;

(3) I (P, T $) \rightarrow \mathrm{N}$ is an Input function that defines an arc directed from a Place to a Transition, where $\mathrm{N}$ is a set of negative integers;

(4) (T, P) $\rightarrow N$ is the Output function that defines the arc directed from Transition to Place; and

(5) Mo: $\mathrm{P} \rightarrow \mathrm{N}$ is the initial marking.

Marking is the assignment of tokens to places of the Petri net. The number and position of tokens may change during the implementation of the Petri network. 
The simulation example refers to Figure 1, where we have in the Petri net:
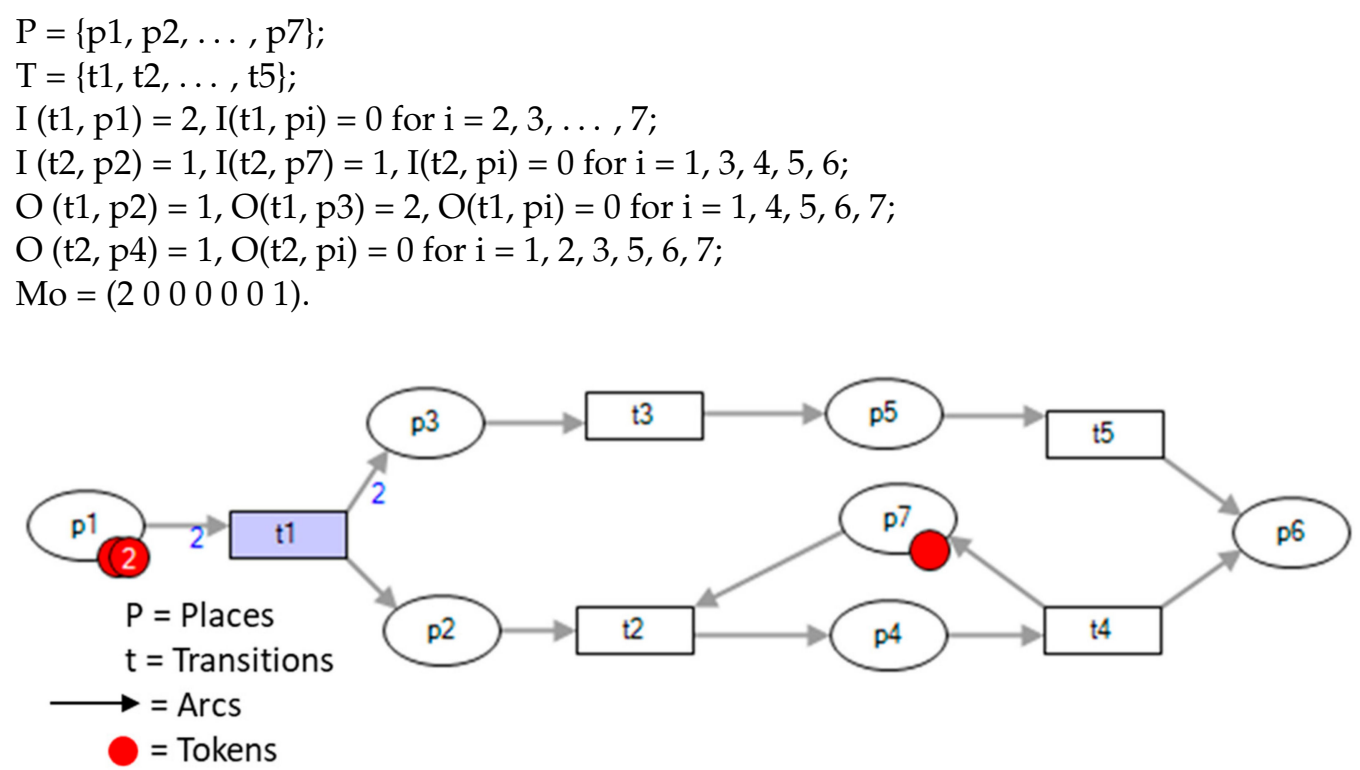

Figure 1. The Petri nets simulation circuit as an example, using HiPS software [30].

According to Wang (1998), "Petri nets were named after Carl A. Petri, who defined a general-purpose mathematical tool for describing relations existing between conditions and events. This work was done in the years 1960-1962. Since then, Petri nets have resulted in considerable research because they can be used to model properties such as process synchronization, asynchronous events, sequential operations, concurrent operations, and conflicts, or resource sharing. These properties characterize Discrete Event Dynamic Systems (DEDS). This, and other factors, makes Petri nets a promising tool and technology for applying to various types of DEDS. Petri nets provide a powerful communication medium between the user, typically requirements engineer, and the customer as a graphical tool. Instead of using ambiguous textual descriptions or mathematical notation difficult to understand by the customer, complex requirements specifications can be represented graphically using Petri nets. This, combined with computer tools, allows interactive graphical simulation of Petri nets and puts the development engineers a powerful tool to assist in complex engineering systems' development process. The graphical representation also makes Petri nets intuitively very appealing. They are straightforward to understand and grasp-even for people who are not very familiar with Petri nets' details. This is because Petri net diagrams resemble many of the drawings that designers and engineers make while constructing and analysing a system" [31]. Volovoi (2003) dealt with "the dynamic modelling of degrading and repairable complex systems as modularity allows a focus on the needs of a system reliability modelling and tailoring of the modelling formalism accordingly" [32]. Chew et al. (2007) mentioned that "Petri Nets provide a logical, easily understood, and compelling way of predicting the reliability of a system or platform" [33]. Garg (2012) mentions that "Petri Nets tool is applied to represent the asynchronous and concurrent processing of the order instead of the fault tree analysis" [34]. Leigh and Dunnett (2016) mentioned that "the study has aimed to develop a model using Petri Nets to determine the feasibility of adopting this technique to model the maintenance processes efficiently" [35]. Ren et al. (2014) mentioned that "if a Petri Nets are required to model processes that have a random (or pseudorandom) nature to them, and this randomness follows a specific pattern such as a statistical distribution, the transitions can sample their switching times from this distribution" [36]. Sadou et al. (2009) mentioned that "this new representation of the Petri net with formulae of linear logic allows us to define the notion of scenario formally. To obtain a minimal situation, we have considered three elements: (i) the order of events governed by a useful relation of cause and effect in the system, (ii) the list of activities of the scenario must be minimal (i.e., without loop events), and (iii) the 
final marking corresponding to the feared state must be minimal" [37]. Eisenberger and Fink (2017) stated that "Petri nets are such a mathematical tool that has been applied for maintenance modelling and simulations of different applications. Several types of Petri nets with different properties have been introduced" [38]. Pinto et al. (2021) stated that "the importance of Petri Nets as a powerful tool in maintenance management, providing analysis and simulation of the systems to increase the reliability and availability of the individual assets and their operations" [30]. Farinha (2018) showed the example using Petri nets on the electrical circuit through "an Emergency Generator that, as is known, starts operating when the external mains voltage from below a certain value about the nominal voltage. In the example, the value assumed for starting the Emergency Generator is $350 \mathrm{~V}$. When the value of the voltage of the external electrical network from below this value, the Generator starts, turning off when the electrical network's value is above that. For this purpose, the following situations are assumed for the Emergency Generator: The Generator can be in two possible operational states: in standby and operation (generating electricity); two situations give rise to those states: mains voltage above $350 \mathrm{~V}$ (>350 V) and below this value $(<350 \mathrm{~V})$; Other possible states, such as malfunction, are not considered. Figure 2 illustrates the state diagram and the Petri Net for the preceding situations, respectively" [39].

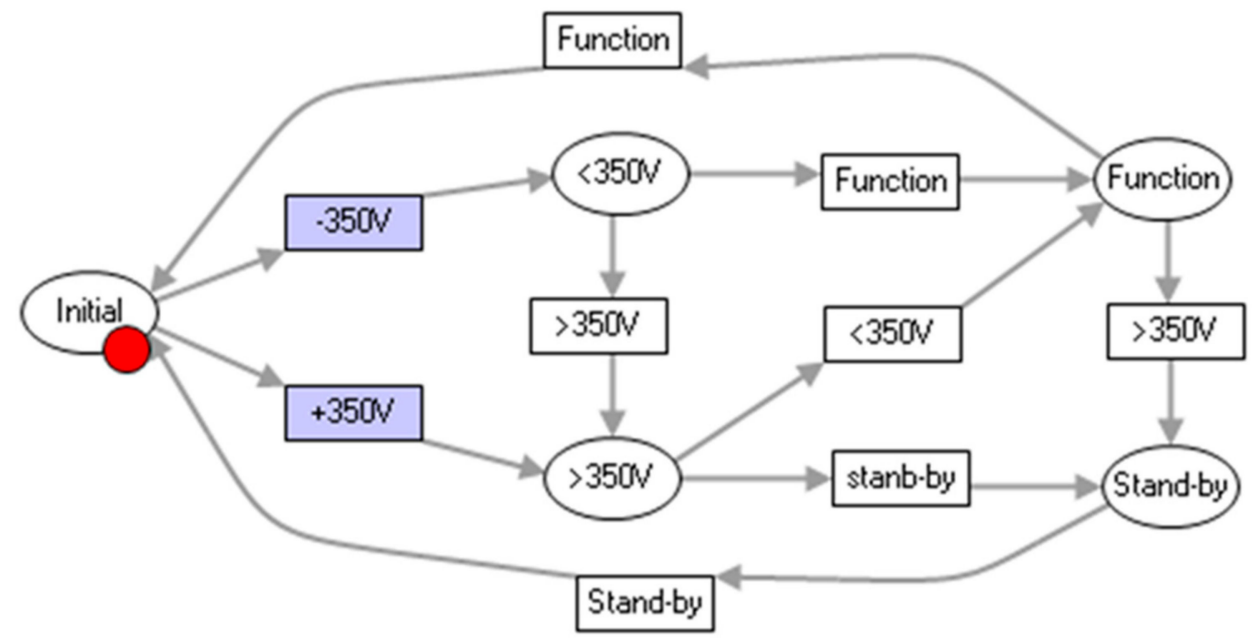

Figure 2. Example of a Petri net on standby (red dot = token = energy of electrical power) [39].

\subsection{Fuzzy Inference System (FIS) and Fuzzy Petri Nets}

Fuzzy Petri Nets is a combination of two different sciences-the set of fuzzy logic and Petri nets theory - which are held to provide answers to vague or unclear problems in a system that is about to be examined. Therefore, we use fuzzy Petri nets to see and provide solutions to problems that are not clear, such as an asset or system that does not have historical data but wants to get a definite answer regarding the reliability and reliability of maintenance to improve the performance of these assets. Also, several previous researchers put forward their ideas in articles they wrote as follows. Cannarile et al. (2017) "propose a method based on the Fuzzy Expectation-Maximization (FEM) algorithm, which integrates the evidence of the field inspection outcomes with information taken from the maintenance operators about the transition times from one state to another. Possibility distributions are used to describe the imprecision in the expert statements" [40]. Ladj et al. (2017) proposed "a new interpretation of PHM outputs to define machine degradations that are corresponding to each job. Moreover, to consider several sources of uncertainty in the prognosis process, the authors choose to model PHM outputs using fuzzy logic. Motivated by the computational complexity of the problem, Variable Neighbourhood Search (VNS) methods are developed, including well-designed local search procedures" [41]. Touat et al. (2017) mentioned that "to solve the problem, we developed two fuzzy genetic algorithms that are based on respectively the sequential and total scheduling strategies. The one 
respecting the sequential approach consists of two phases. In the first phase, the integrated production and maintenance schedules are generated. In the second one, the human resources are assigned to maintenance activities. The second algorithm respecting a total strategy consists of developing the integrated production and maintenance schedules that explicitly satisfy the human resource constraints" [42]. Jabari et al. (2019) mentioned that "Based on the results obtained in the case study, it can conclude that the fuzzy set for calculation is more rigorous than the qualitative results. The calculated unified qualitative and fuzzy risk number shows that the plant was classified as semi-critical. It obtained the highest fuzzy risk number of 99.1452 for both blowers (BW 2021 and BW 2023 A) assets failure" [43]. Ratnayake and Antosz (2017) mentioned that, "also, a fuzzy logic-based risk rank calculation approach has been presented. The suggested RBM approach, together with the fuzzy inferencing process, enables us to minimize suboptimal calculations when the input values are at the boundaries of the particular ranges. Fuzzy membership functioned together with the rule base. It enabled to insert numbers with the least uncertainty" [44]. Seiti et al. (2017) mentioned that, "for this purpose, a model based on Fuzzy Axiomatic Design (FAD) is presented, wherein each evaluation has both optimistic and pessimistic fuzzy scores, as the fuzzy evaluations themselves have risks. To improve the accuracy of the presented method, a new concept called "acceptable risk" has been suggested" [45]. Babashamsi et al. (2016) stated that "to determine the weights of the indices, the fuzzy AHP is used. Subsequently, the alternatives' priorities are ranked according to the indices weighted with the VIKOR model" [46]. According to Cordón (2011), "The current contribution constitutes a review on the most representative genetic fuzzy systems relying on Mamdani-type fuzzy rule-based systems to obtain interpretable linguistic fuzzy models with a good accuracy" [47]. Zahabi and Kaber (2019) mentioned that "use the Mamdani max-min inference method to calculate a 'risk reliability (R-R) score based on a fuzzy definition of frequency of hazard occurrence, the severity of hazard outcomes, and system reliability. The application of the proposed model is presented in the context of a complex-human-in-the-loop system using the MATLAB fuzzy logic toolbox" [48]. According to Akgun et al. (2012), "For this purpose, an easy-to-use program, 'MamLand,' was developed for the construction of a Mamdani fuzzy inference system and employed in MATLAB. Using this newly developed program, it is possible to construct a landslide susceptibility map based on expert opinion" [49]. According to Kacimi et al. (2020), "The Mamdani fuzzy system is known as a linguistic model where the semantic meaning of the fuzzy rules is an intrinsic characteristic that must be retained during the learning process while seeking for high accuracy" [50]. Lu and Sy (2009) mentioned that "A fuzzy logic approach is adopted to handle the uncertainty conditions. To meet the requirement of real-time decision-making, the fuzzy project programs were coded and compiled into DLL files" [51]. Dhimish et al. (2018) stated that "Mamdani fuzzy logic system interface and Sugeno type fuzzy system. Both examined fuzzy logic systems show approximately the same output during the experiments. However, there are slight differences in developing each type of the fuzzy system such as the output membership functions and the rules applied for detecting the type of the fault occurring in the PV plant" [52]. Kraidi et al. (2020) stated that "A Computer-Based Risk Analysis Model (CBRAM) was designed to analyse the risk influencing factors using a fuzzy logic theory to consider any uncertainty that is associated with stakeholders' judgments and data scarcity. The CBRAM has confirmed the most critical risk influencing factors, in which this study has explained the effective methods to manage them" [53]. Khosravanian et al. (2016) stated that "The Mamdani-type FIS requires defuzzification, whereas the Sugeno-type FIS applies a constant weighted-average technique avoiding defuzzification. The results for the two field cases evaluated convincingly demonstrate that the Sugeno-type FIS is superior to the Mamdani-type FIS for WOB prediction using the same input data and membership functions" [54].

About this type of approach, the research developed by Teo et al. [55-57] must be considered as very relevant, regardless of to be focused on mainly in energy management, 
namely for a grid-connected microgrid with renewable energy sources and energy storage system, including the design of fuzzy logic-based controllers to be embedded in a gridconnected microgrid with renewable and energy storage capability.

From the many approaches done by many researchers and the authors' research, it can consider that fuzzy Petri nets have a very high potential to help solve complex reliability problems inside the systems.

\subsection{The HiPS Software Simulator Description}

According to the HiPS (Hierarchical Petri net Simulator), the "tool was developed by the Department of Computer Science and Engineering, Shinshu University, being a tool for Petri nets design and analysis; it was developed using Microsoft Visual C \# and $\mathrm{C}++$. HiPS tool has a very intuitive GUI, which enables hierarchical and/or timed-net design. HiPS tool has also functioned of static/dynamic analysis: T-invariant detection, Reachability path analysis, deadlock state detection, and k-boundedness analysis. Also, it is possible to perform a random walk simulation with each firing step" [58]. The definition of the Petri net model using the HiPS software can be seen in Figure 3.

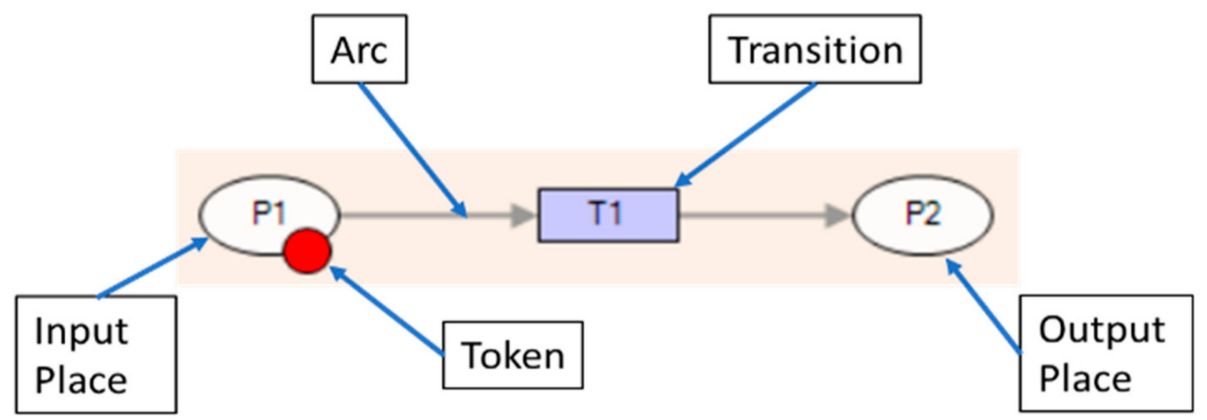

Figure 3. The definitions tools in HiPS.

\section{Electrical Power System of a Big European Hospital}

\subsection{Characterization of the Hospital}

The big European hospital is a medical care building that has a total construction area of $90,000 \mathrm{~m}^{2}$.

This paper focuses on the emergency power supply system (EPSS) of the hospital, which has the following equipment: three units of 1000 KVA generators; two units of UPS (uninterrupted power supply) with $300 \mathrm{KVA}$; one unit of UPS of $8 \mathrm{KVA} ; 20$ units of UPS of $20 \mathrm{KVA}$; one unit of ATS (automatic transfer switch); three transformer units; two PT (power transfer); three LVDB (low-voltage distribution board) input units; six LVDB central output units and other peripheral instruments (correction battery, LV distribution network, indoor lighting (normal/emergency), output and obstruction signalling, normal/emergency outlets); and ground network. The paper uses Petri net time methods and fuzzy logic to analyse and diagnose the power system's operation and reliability and propose a new design to improve its availability [30].

\subsection{Modelling of the Hospital's Electrical System Using Block Diagrams}

The main contribution of the Petri nets system is based on their ability to simulate the process and to analyse complex structures. Figure 4 shows the process block flow diagram of the electrical power system of the hospital under study. 


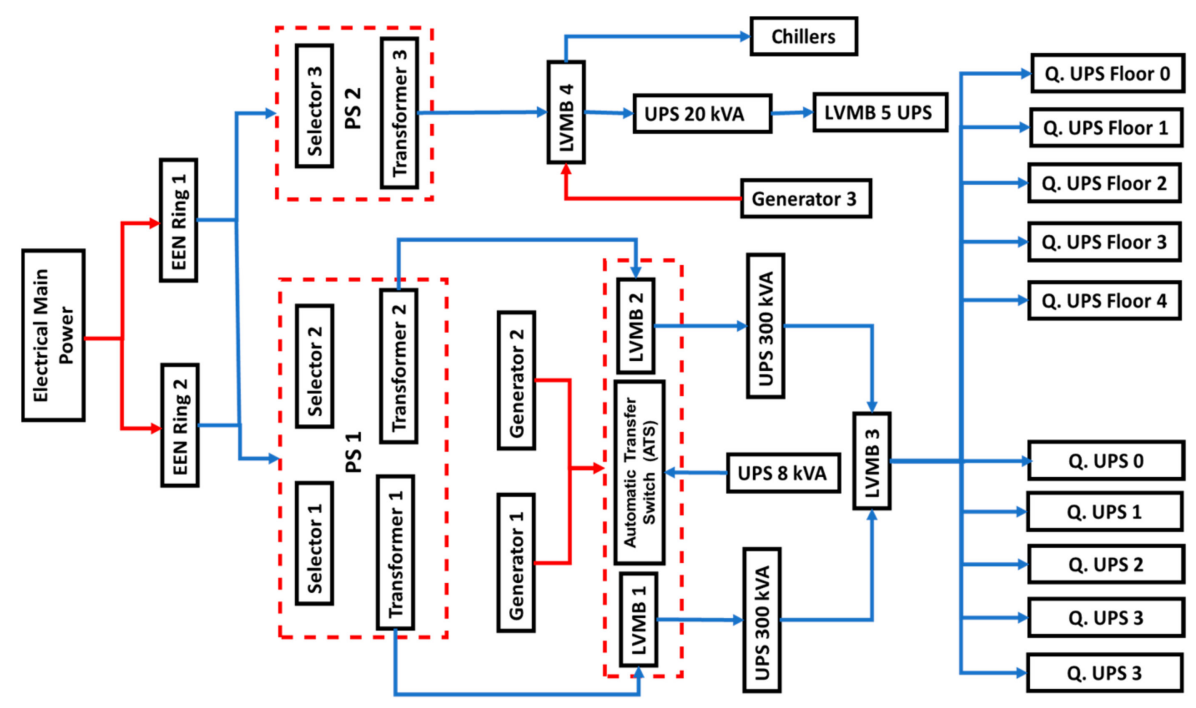

Figure 4. Asset process flow diagram (APFD) [30].

\subsection{The Group of Generators, Automatic Transfer Switch, and UPS}

In case of power failure of the external electrical energy supplier, the hospital is equipped with three generators, two of $1000 \mathrm{kVA}$ and one of $500 \mathrm{kVA}$, powered by diesel engines. The command and transfer board of the most potent power groups have also an installed synchronization system between the two groups that can operate in parallel after synchronization between both groups (Figure 5) [30].

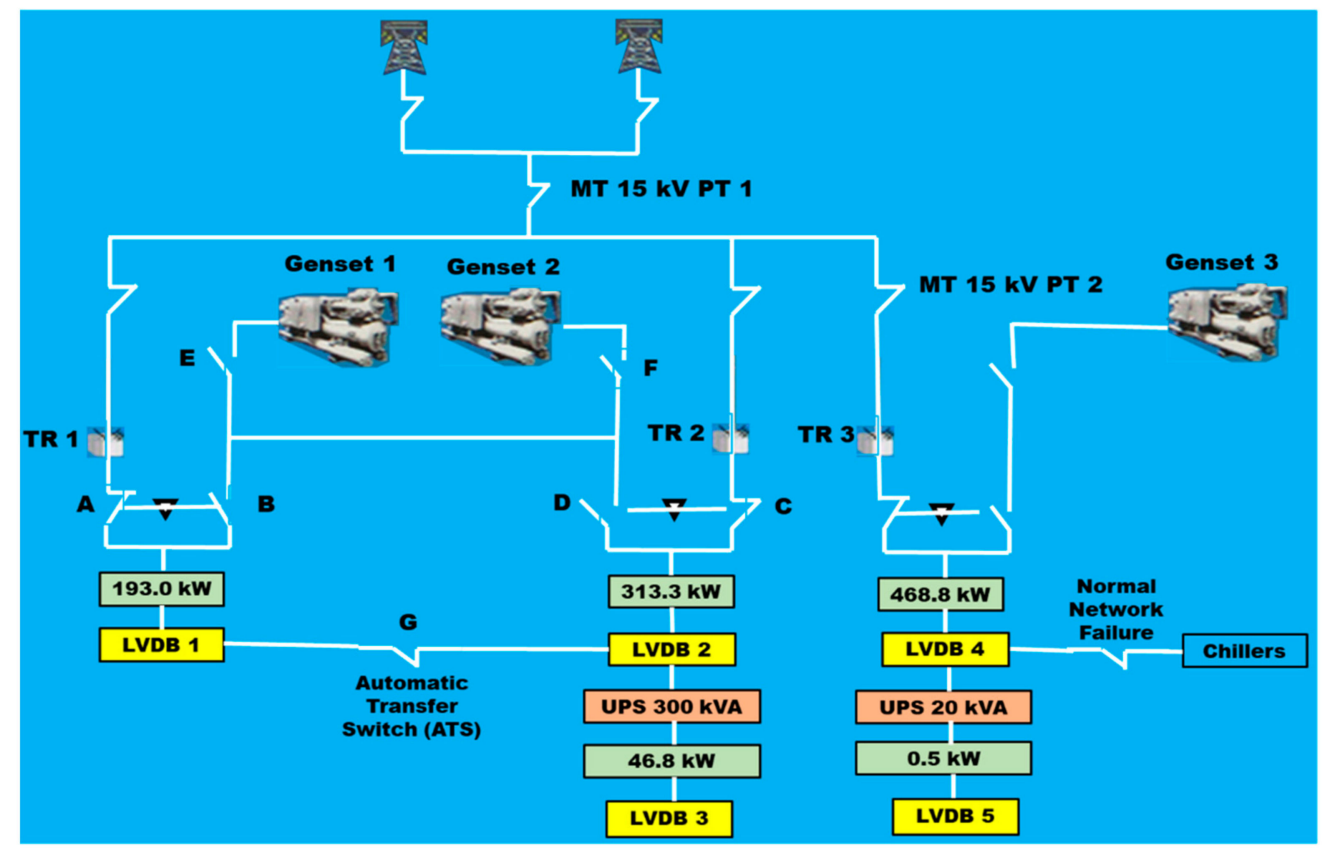

Figure 5. Diagram of the electric power system in the hospital [30].

\section{Modelling the Hospital's Electrical System Using Petri Nets}

4.1. Modelling the Hospital's Electrical System by Petri Nets

In the present case, the physical assets under study have maintenance procedures to guarantee their adequate reliability and availability conditions and mitigate failures (Figure 6). 


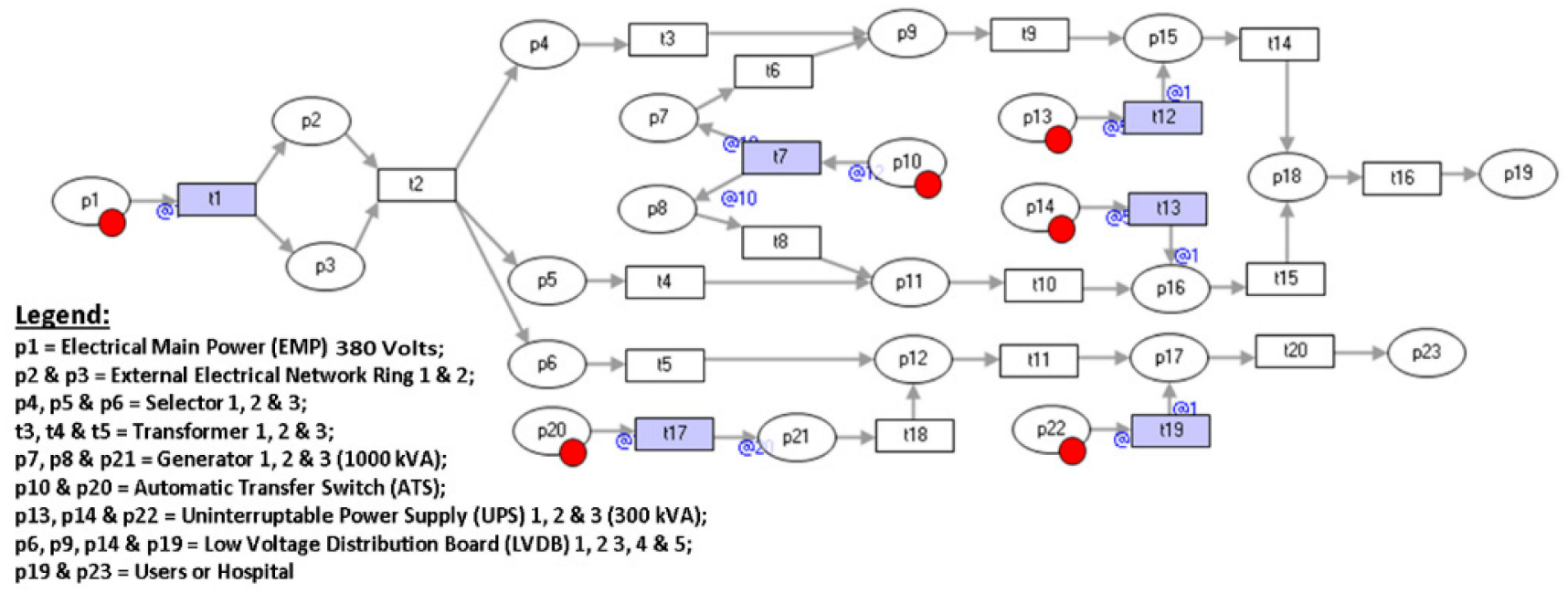

Figure 6. Modelling and simulation in the Petri net of the electrical power system [30].

\subsection{The Hospital Electrical System Block Diagrams}

As can be seen in Figure 7, the ATS manages the generators-if it does not work, then the generators must be activated manually, which hurts the system. Additionally, it can be emphasized that only one ATS is installed. Thus, the question arises: how do the above circuit behaviours answer to the expected security system? To respond to this question, the present situation was simulated and a solution to solve the identified handicap with block diagrams, as shown in Figures 8 and 9, is proposed [30].

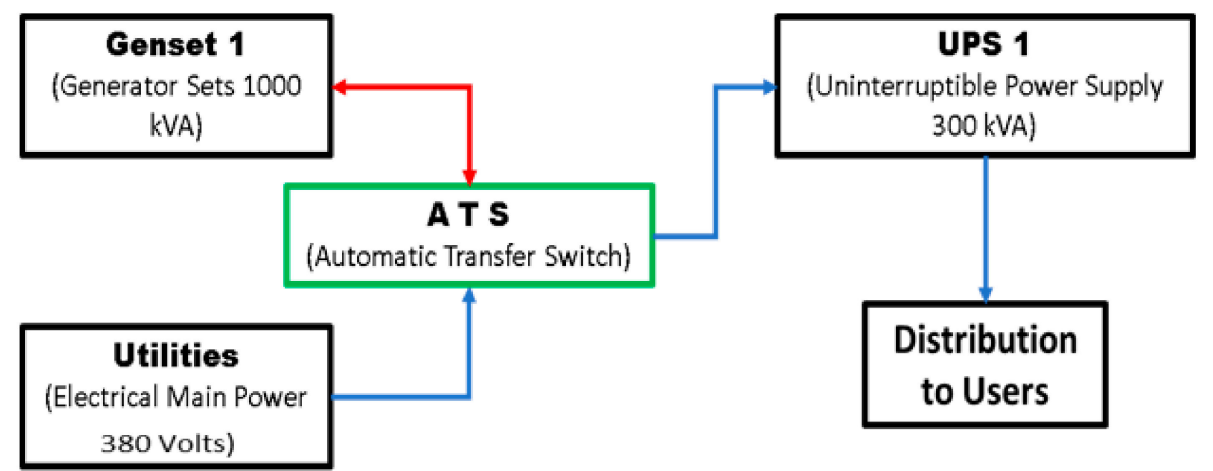

Figure 7. Design with an evident weakness, with one ATS, one UPS, and one Genset [30].

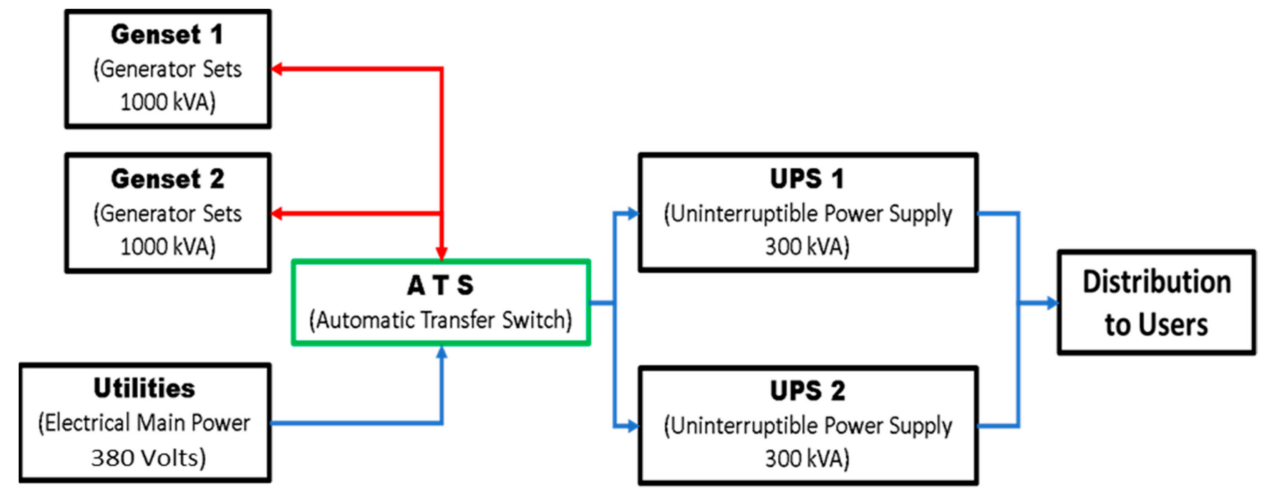

Figure 8. Weakness module with increased reliability, through 1 ATS, 2 UPSs, and 2 Gensets [30]. 


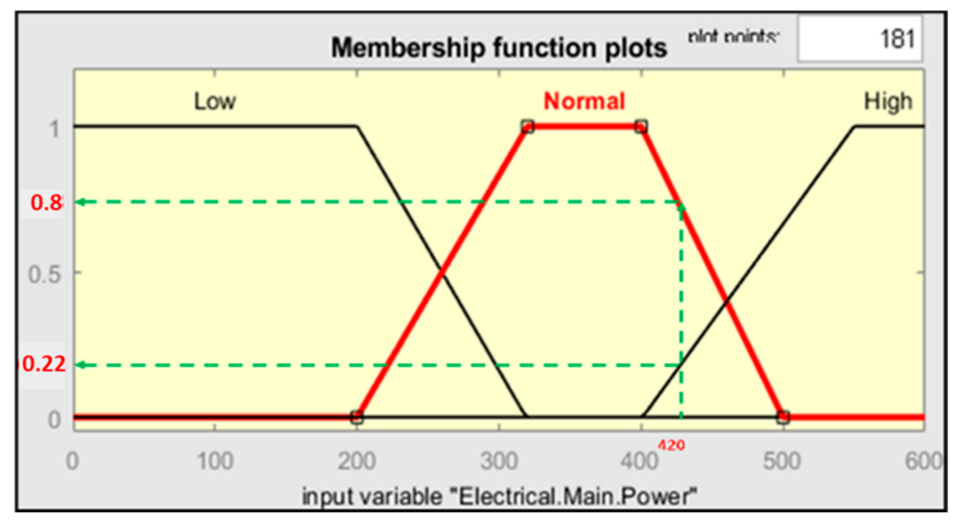

Figure 9. Electrical main power.

In the block diagram of Figure 7, the hypothesis of a fault in the main electrical power is emphasized when the UPS takes over the primary function. In this situation, the ATSs activate the generator that replaces the UPS while waiting until the main electrical power is on again; unfortunately, if one of the ATS, UPS, and generator fails, then a fatal accident occurs, which permits to infer that this is a fragile module.

In the block diagram of Figure 8, if there is a current fault from the main power, UPS 1, 2 , and 3 will turn on the main power's functions. Then, ATS activates Genset 1, 2, and 3, replacing the UPS function, while waiting for an intervention from the maintenance team; if one of the UPS, Genset, or ATS fails, then it will be replaced by the other UPS (Genset and ATS) because there is a redundancy of three units; thus, the probability of fatality accidents is extremely low. This design can be considered a good design because it is deemed very reliable; however, its cost and maintenance are more expensive because it needs more equipment to be installed. It can be concluded that the components of the system are critical to the electrical hospital functioning, and the ATS is the most critical item.

Because of the preceding, the electrical sequences that must be carefully targeted for research to identify the main functions and failures of each module for the installed load are discussed and analysed. However, because the hospital does not provide historical data, Petri nets are used to analyse this case study.

\subsection{Modelling and Analysing with a Fuzzy Inference System}

For computing, the authors use the MATLAB fuzzy tool and the fuzzy Mamdani method.

\subsubsection{Fuzzification Data Processing}

After analysing the electricity system of the hospital, using Petri nets and the block diagrams design to find the most critical instruments or items in the asset, now we use fuzzy MATLAB to determine how reliable and available the system is according to their several states to determine the input and output functions of the system by the specified setpoint; it will use information and conditions, such as electric main power worth 420 , Genset 1 and 2700, ATS 140, and UPS 1 and 2220. The removal of all inputs and outputs is presented in Figures 9-12.

$$
\begin{gathered}
\mu \operatorname{Normal}(420)=\frac{(500-420)}{(500-400)}=0.8 \\
\mu \operatorname{High}(420)=\frac{(420-400)}{(550-400)}=\frac{20}{150}=0.215
\end{gathered}
$$




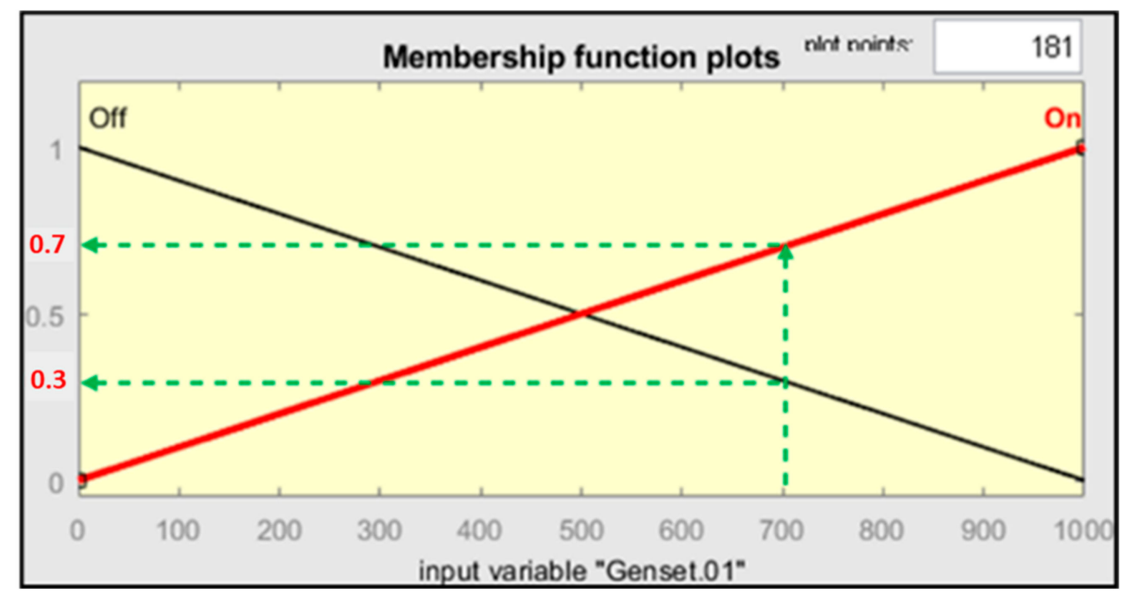

Figure 10. Genset 1 and 2.

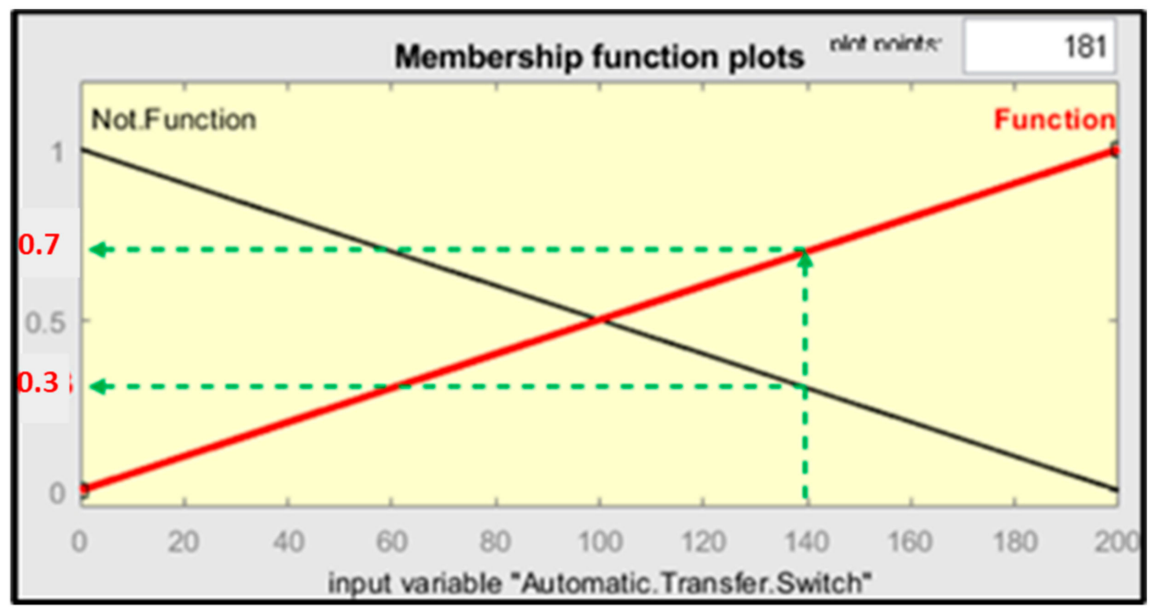

Figure 11. ATS.

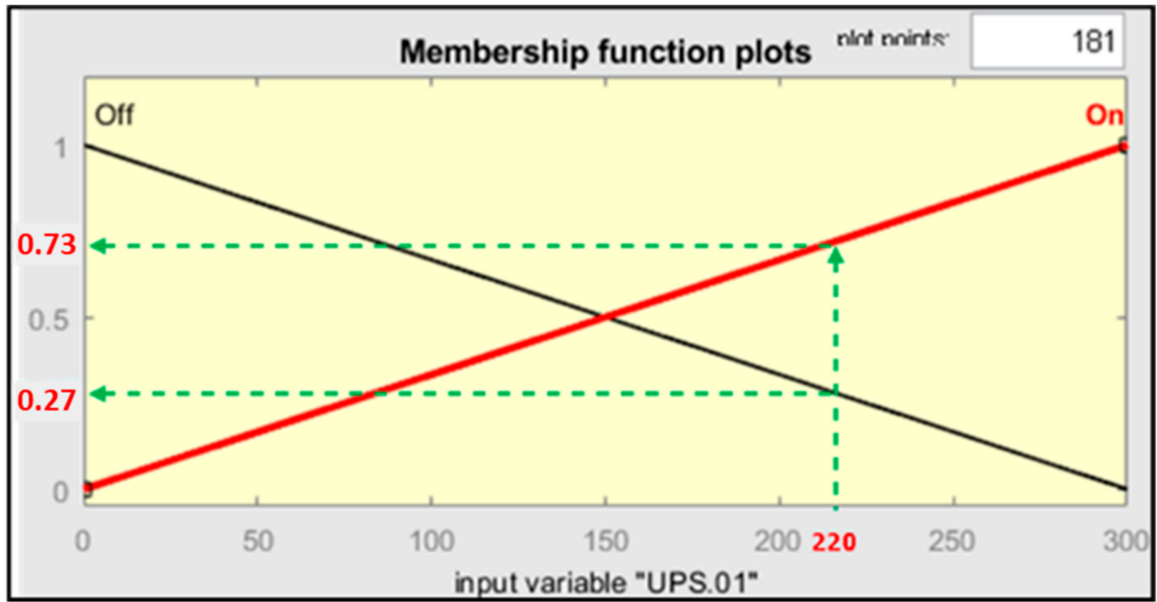

Figure 12. UPS 1 and 2.

Thus, we can conclude that the fuzzy set for input "Electrical Main Power" is as follows:

Fuzzy Low set: $\mu$ Low $(420)=0$

Fuzzy Normal set: $\mu$ Normal $(420)=0.8$

Fuzzy High set: $\mu$ High $(420)=0.215$

$$
\mu O n(700)=\frac{700-0}{1000-0}=\frac{700}{1000}=\frac{7}{10}=0.7
$$




$$
\mu O f f(700)=\frac{1000-700}{1000-0}=\frac{300}{1000}=\frac{3}{10}=0.3
$$

Thus, we can conclude that the fuzzy set for input "Genset $01=$ Genset 02 " is as follows: Fuzzy set On: $\mu O n(700)=0.7$

Fuzzy set Off: $\mu$ Off $(700)=0.3$

$$
\begin{gathered}
\mu \text { Function }(140)=\frac{140-0}{200-0}=0.7 \\
\mu \text { Not Function }(140)=\frac{200-140}{200-0}=0.3
\end{gathered}
$$

Thus, we can conclude that the fuzzy set for input "Automatic Transfer Switch" is as follows: Fuzzy Function set: $\mu$ Function $(140)=0.7$ Fuzzy Not Function set: $\mu O f f(700)=0.3$

$$
\begin{gathered}
\mu O n(220)=\frac{220-0}{300-0}=0.73 \\
\mu O f f(220)=\frac{300-220}{300-0}=0.27
\end{gathered}
$$

Thus, we can conclude that the fuzzy set for input "UPS $01=$ UPS 02 " is as follows:

Fuzzy On set: $\mu O n(220)=0.73$

Fuzzy Off set: $\mu$ Off $(220)=0.27$

If we collect all input variables: Electrical Main Power $=420$, Genset 01 and $02=(700 \times 2)$, Automatic Transfer Switch $=140$, and UPS 01 and UPS $02=(220 \times 2)$. Then we get the following values:

Fuzzy Low set: $\mu$ Low $(420)=0$

Fuzzy Normal set: $\mu$ Normal $(420)=0.8$

Fuzzy High set: $\mu$ High $(420)=0.215$

Fuzzy set On: $\mu \mathrm{On}(700)=0.7$

Fuzzy set Off: $\mu$ Off $(700)=0.3 \times 2$ (the value of two Genset)

Fuzzy Function set: $\mu$ Function (140) $=0.7$

Fuzzy Not Function set: $\mu O f f(700)=0.3$

Fuzzy set On: $\mu O n(220)=0.73$

Fuzzy set Off: $\mu$ Off $(220)=0.27 \times 2$ (the value of two UPS)

So, the Maximum and Minimum Values of the above calculation are as follows (Figure 13): Maximum Value: $\mu 1=0 ; \mu 2=0.8 ; \mu 3=0.7 ; \mu 4=0.7 ; \mu 5=0.7 ; \mu 6=0.73$ and $\mu 7=0.73$ Minimum Value: $\mu 1=0 ; \mu 2=0.215 ; \mu 3=0.3 ; \mu 4=0.3 ; \mu 5=0.3 ; \mu 6=0.27$ and $\mu 7=0.27$.
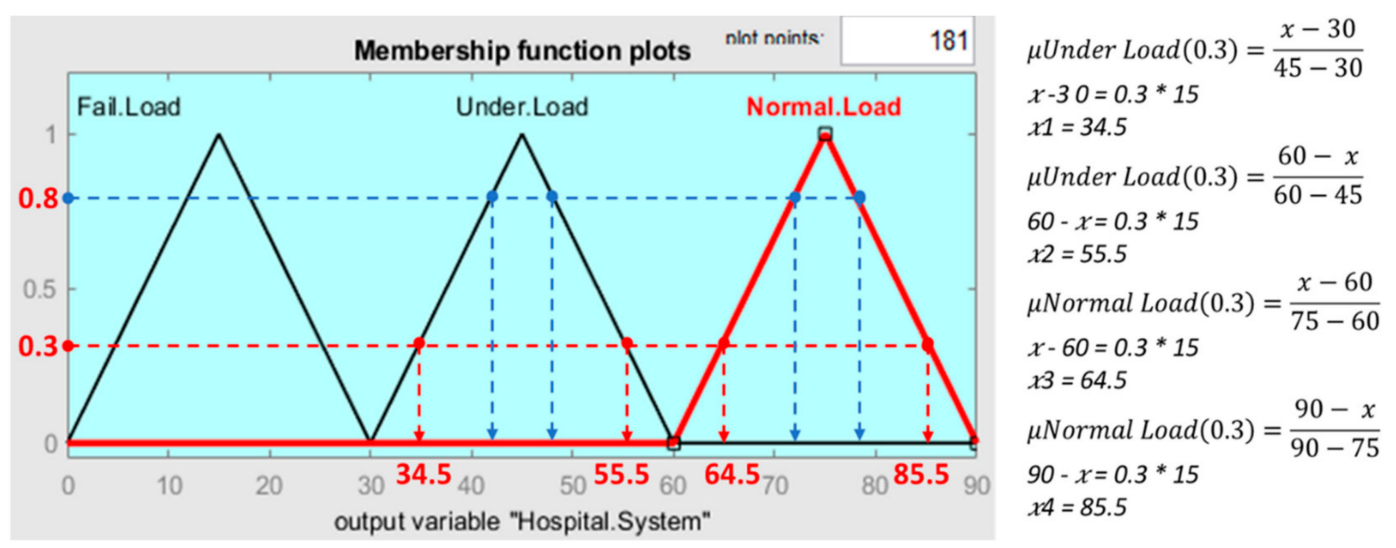

Figure 13. Output maximum and minimum point in fuzzification. 
Using the fuzzy set operator "AND", the value taken is the lowest, and thus:

$\{0.215+(0.3 * 2)+0.3+0.27 * 2)\} / 6=0.28 \approx 0.3$ (minimum total value of input variable) (Figure 14).

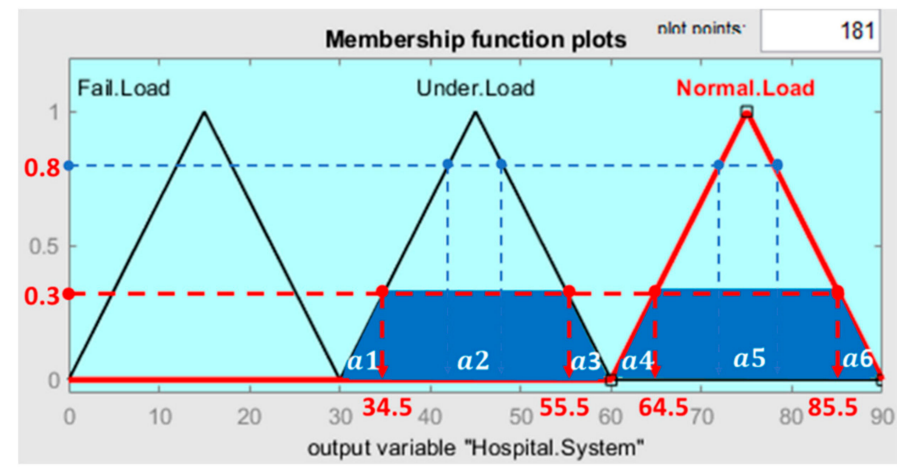

$$
\begin{aligned}
& a 1=\frac{(34.5-30) * 0.3}{2}=0.68 \\
& a 2=(55.5-34.5) * 0.3=6.3 \\
& a 3=\frac{(60-55.5) * 0.3}{2}=0.68 \\
& a 4=\frac{(64.5-60) * 0.3}{2}=0.68 \\
& a 5=(85.5-64.5) * 0.3=6.3 \\
& a 6=\frac{(64.5-60) * 0.3}{2}=0.68
\end{aligned}
$$

Figure 14. Output area of fuzzification.

The defuzzification method used is the centroid of gravity (COG).

In this case, we used the minimum value of $\mu$ because the rules "AND" follow fuzzy logic requirements. $\mu 7=0.27$

Minimum Value: $\mu 1=0 ; \mu 2=0.215 ; \mu 3=0.3 ; \mu 4=0.3 ; \mu 5=0.3 ; \mu 6=0.27$ and

$$
Z^{*}=\frac{(0.215 * 34.5)+(0.3 * 55.5)+(0.3 * 64.5)+(0.27 * 85.5)}{(0.215+0.3+0.3+0.27)}=61.3
$$

The other way to solve the Centroid of Gravity method is using calculus mathematics as follows:

$$
\mu(z)=\left\{\begin{array}{lr}
0, & x \leq \text { or } x \geq 90 \\
\frac{x-30}{45-30}, & 30 \leq x \leq 34.5 \\
0.3, & 34.5 \leq x \leq 55.5 \\
\frac{60-x}{60-45}, & 55.5 \leq x \leq 60 \\
\frac{x-60}{75-45}, & 60 \leq x \leq 75 \\
0.3, & 64.5 \leq x \leq 85.5 \\
\frac{90-x}{90-75}, & 85.5 \leq x \leq 90
\end{array}\right.
$$

$$
\mu(z)=\left\{\begin{array}{lr}
0, & x \leq \text { or } x \geq 90 \\
0.067 x-2, & 30 \leq x \leq 34.5 \\
0.3, & 34.5 \leq x \leq 55.5 \\
4-0.067 x, & 5.5 \leq x \leq 60 \\
0.067 x-4, & 60 \leq x \leq 75 \\
0.3, & 64.5 \leq x \leq 85.5 \\
6-0.067, & 85.5 \leq x \leq 90
\end{array}\right.
$$

The defuzzification method uses the centroid of gravity (COG):

$$
\begin{gathered}
M 1=\int_{30}^{34.5}(0.0666 z-2) z d z=\int_{30}^{34.5}\left(0.00666 z^{2}-2 z\right) d z=0.0222 z^{3}-\left.z^{2}\right|_{30} ^{34.5}=21.9625 \\
M 2=\int_{34.5}^{55.5}(0.3) z d z=\int_{34.5}^{55.5}(0.3 z) d z=0.15 z^{2}-\left.z^{2}\right|_{34.5} ^{55.5}=283.5 \\
M 3=\int_{55.5}^{60}(4-0.0666 z) z d z=\int_{55.5}^{60}\left(4 z-0.00666 z^{2}\right) d z=2 z^{2}-\left.0.0222 z^{3}\right|_{55.5} ^{60}=39.4761 \\
M 4=\int_{60}^{64.5}(0.0666 z-4) z d z=\int_{60}^{64.5}\left(0.00666 z^{2}-4 z\right) d z=0.0222 z^{3}-\left.z^{2}\right|_{60} ^{64.5}=41.362 \\
M 5=\int_{64.5}^{85.5}(0.3) z d z=\int_{64.5}^{85.5}(0.3 z) d z=\left.0.3 z^{2}\right|_{64.5} ^{85.5}=472.5
\end{gathered}
$$


$M 6=\int_{85.5}^{90}(6-0.0666 z) z d z=\int_{85.5}^{90}\left(6 z-0.00666 z^{2}\right) d z=3 z^{2}-\left.0.0222 z^{3}\right|_{85.5} ^{90}=61.0356$

Calculation of the centre point (centroid of gravity):

$$
\begin{gathered}
Z^{*}=\frac{(M 1+M 2+M 3+M 4+M 5+M 6)}{(a 1+a 2+a 3+a 4+a 5+a 6)} \\
Z^{*}=\frac{(21.9625+283.5+39.4761+41.362+472.5+61.0356)}{(0.68+6.3+0.68+0.68+6.3+0.68)}=60
\end{gathered}
$$

Therefore, the centre of gravity of the calculated drawing area is at point $x=60$ and point $\mathrm{y}=0$ as a balance of the average electrical current in the said hospital system (Figure 15).

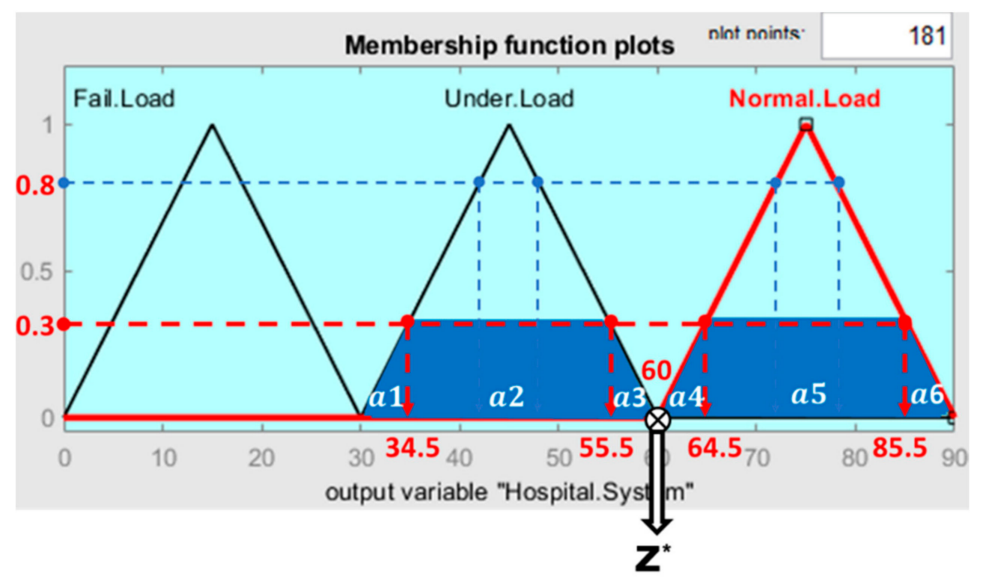

Figure 15. Representing the centre of gravity at coordinates $x=60$ and $\mu=0$ of the drawing.

\subsubsection{Fuzzy Logic Designer}

Fuzzy logic designer in this study involves parameters including six "inputs": (a) electrical main power (350 MVA); (b) two Gensets 1 and Gensets 2 (1000 KVA); (c) one automatic transfer switch (ATS); and (d) two UPS 1 and UPS 2 (300 KVA). The input is shown in Figure 16.

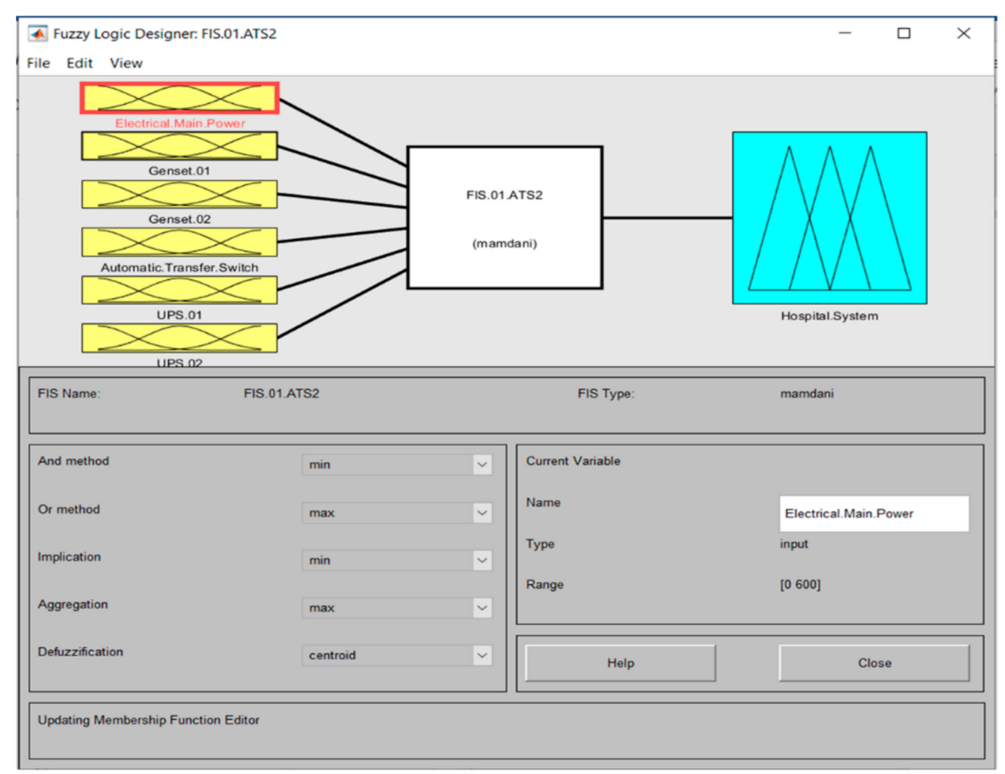

Figure 16. Fuzzy logic design variable inputs and output. 


\subsubsection{Membership Function Editor}

The Membership Function Editors of the fuzzy logic design input variables are shown in Figure 17a-f.

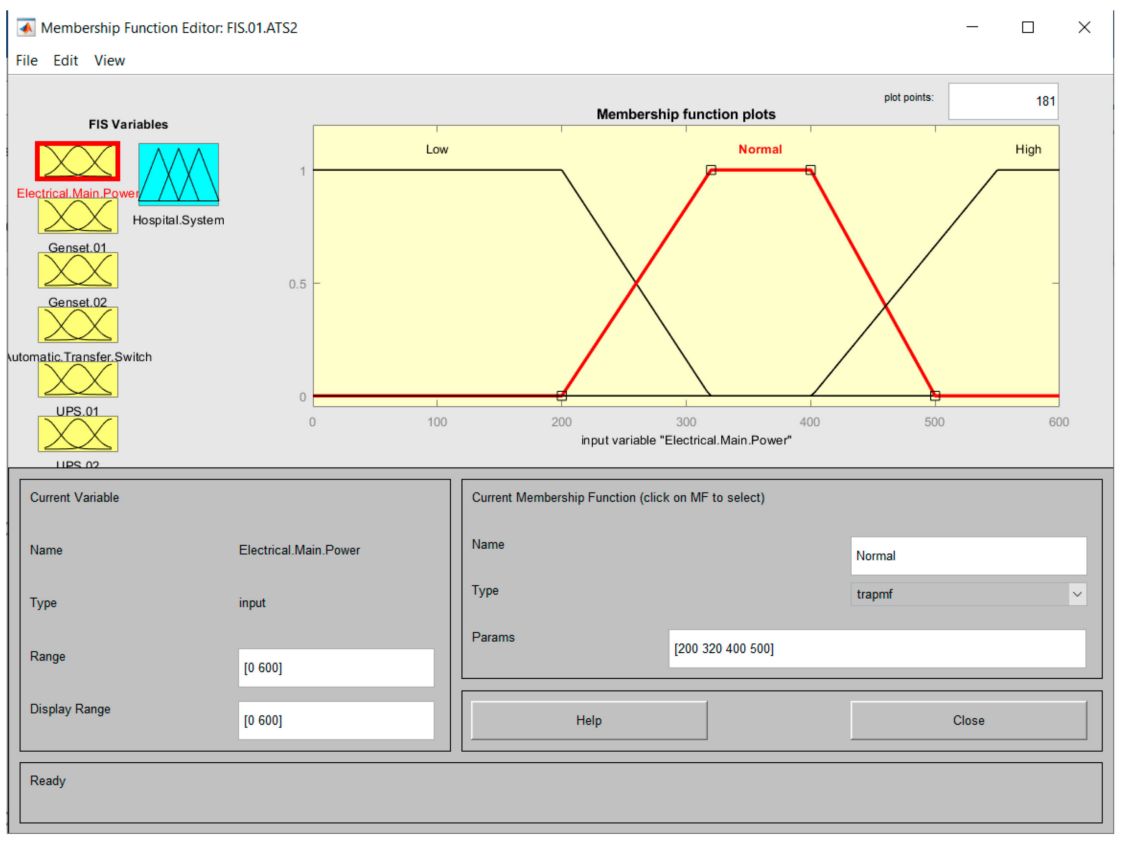

(a)

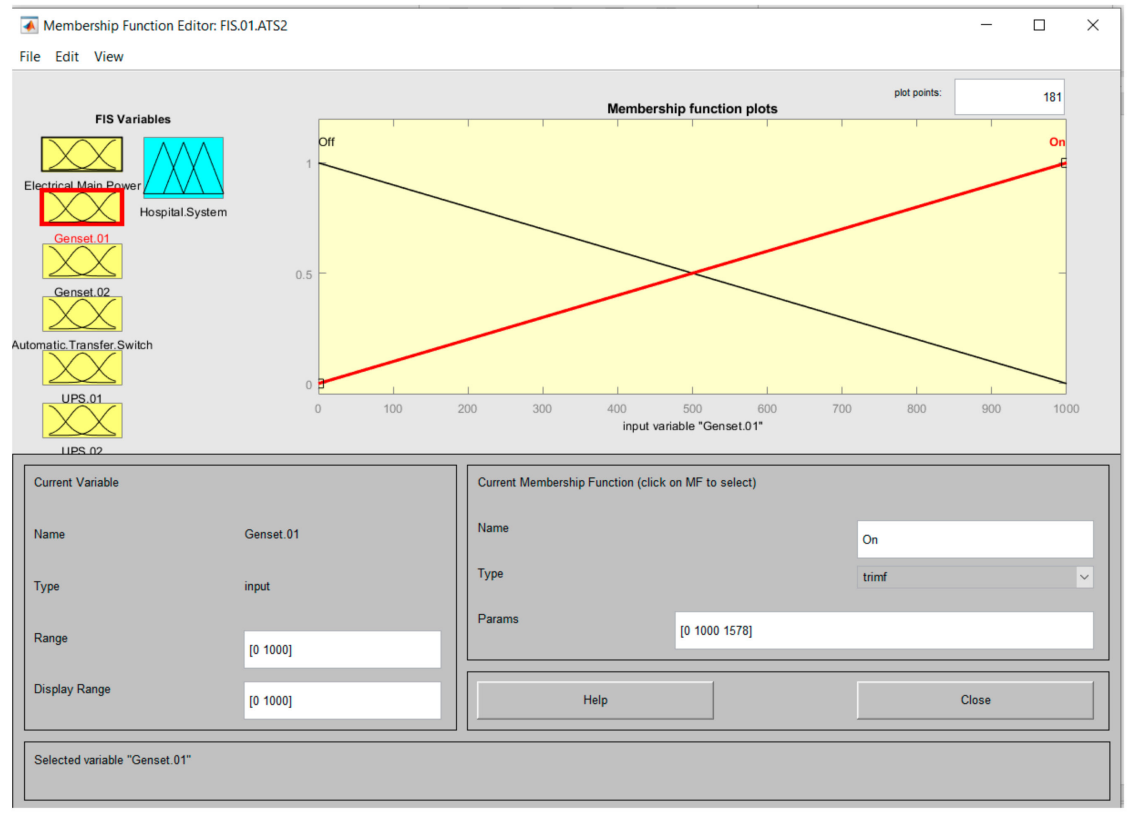

(b)

Figure 17. Cont. 


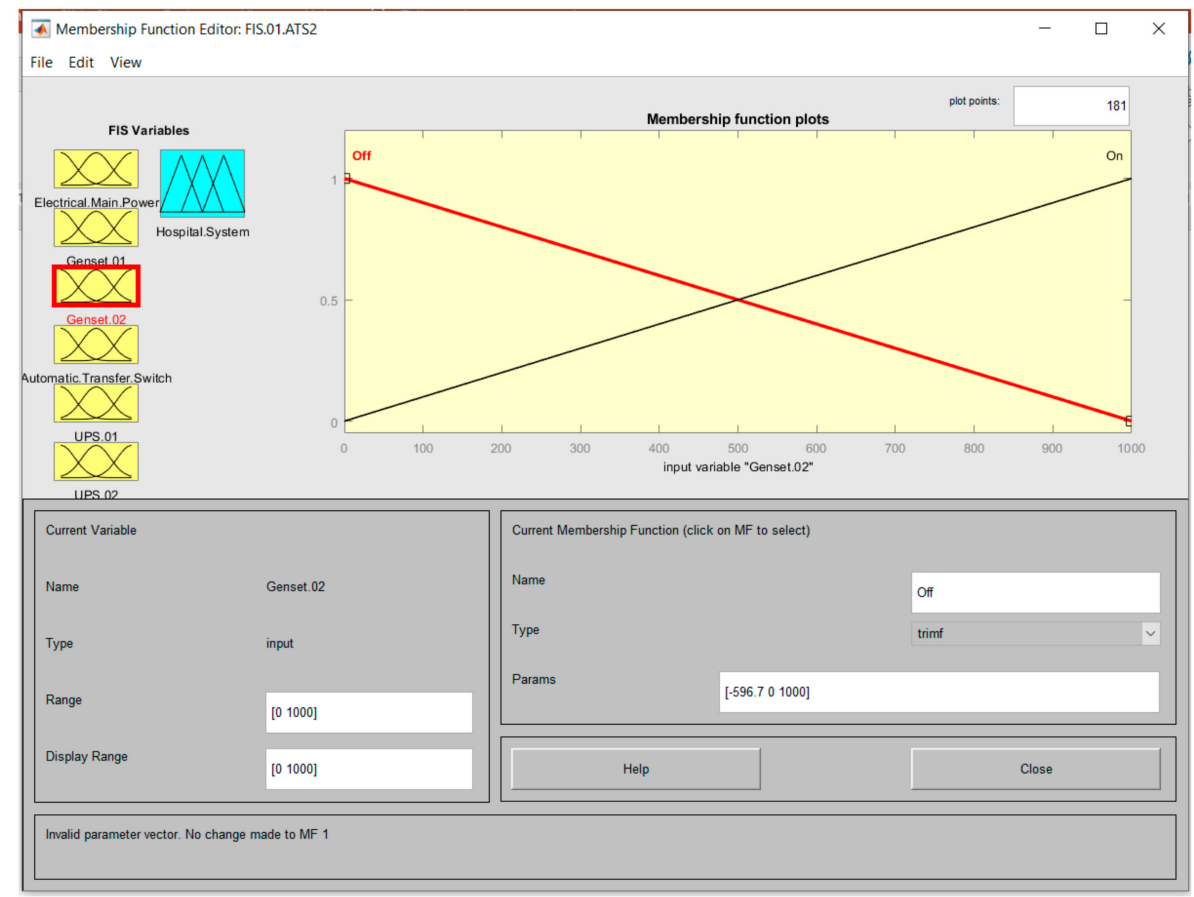

(c)

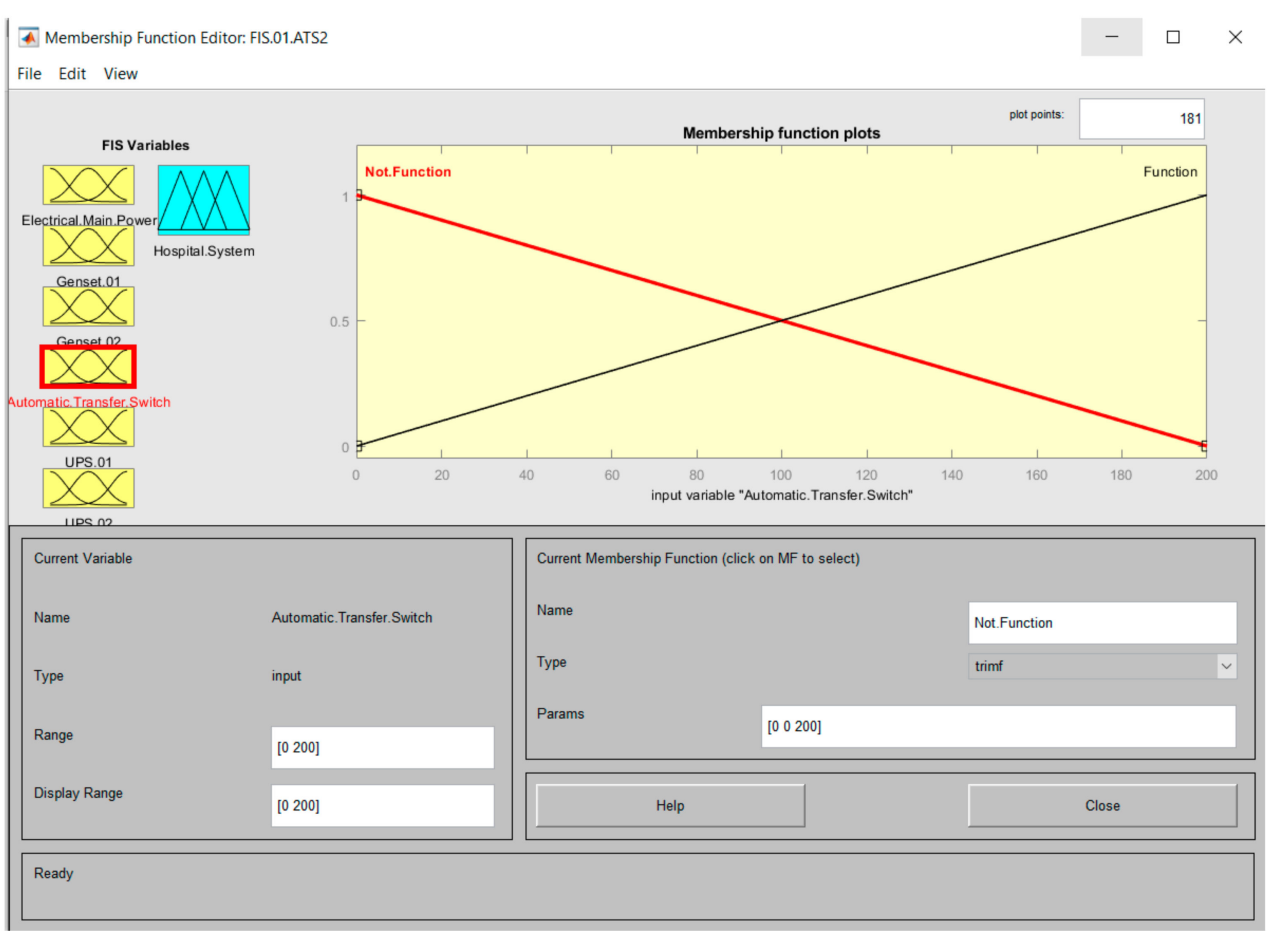

(d)

Figure 17. Cont. 


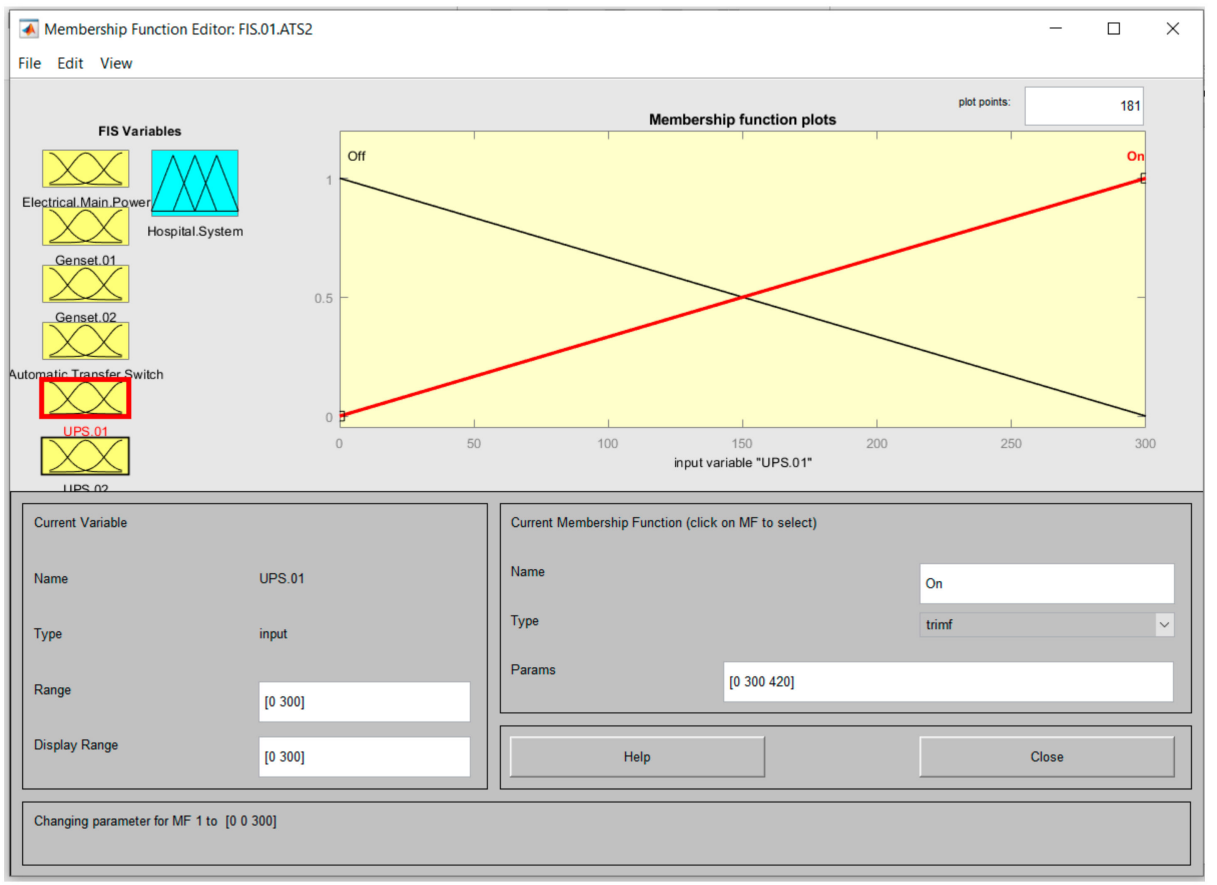

(e)

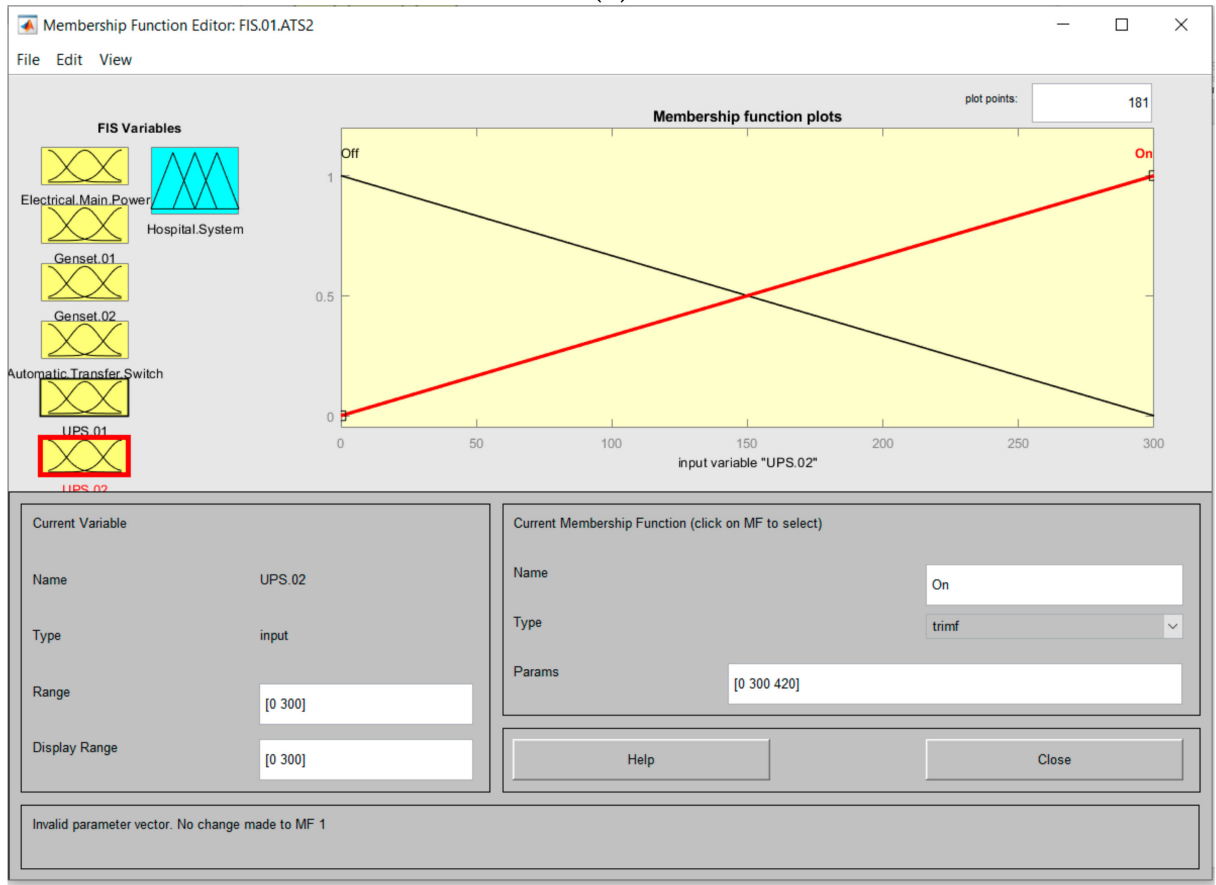

(f)

Figure 17. Membership Function Editor input variable: (a) electrical main power; (b) Genset 1; (c) Genset 2; (d) automatic transfer switch; (e) UPS 1; and (f) UPS 2.

In Figure 17, from (a) to (f), it is clear that the elements contained therein are intervals and parameters; however, the approach can be completed with Table 1, from (a) to (f), which corresponds to each corresponding item of Figure 17, from (a) to (f), respectively.

The Membership Function Editor of the fuzzy logic design for "output" variables is designed based on the input voltage variation: if the voltage received on the system for Under load is $34.5 \%$ up to $55.5 \%$ and at Normal load is $64.5 \%$ up to $85.5 \%$, then the output that appears in the fuzzy MATLAB simulation is shown in Figure 18.

In Figure 18, it is clear that the elements enclosed in it are the intervals and parameters; however, they can be supported by Table 2 . 
Table 1. Membership Function Editor corresponding to Figure 17, respectively.

\begin{tabular}{|c|c|c|}
\hline \multicolumn{3}{|c|}{ Imput Fuction “EMP” } \\
\hline Situation & Normal & High \\
\hline Range & $(0600)$ & $(0600)$ \\
\hline Parameters & $(200320400500)$ & $(401550699799)$ \\
\hline \multicolumn{3}{|c|}{ (a) } \\
\hline \multicolumn{3}{|c|}{ Imput Fuction “Genset 1 = Genset 2" } \\
\hline Situation & Off & On \\
\hline Range & $(0$ 1000) & (0 1000) \\
\hline Parameters & $(-51201000)$ & (0 1000 1578) \\
\hline \multicolumn{3}{|c|}{$(b-c)$} \\
\hline \multicolumn{3}{|c|}{ Imput Fuction "ATS" } \\
\hline Situation & Not Function & Function \\
\hline Range & $(0$ 200) & (0 200) \\
\hline Parameters & $\left(\begin{array}{llll}-80 & 0 & 200\end{array}\right)$ & (0 200280$)$ \\
\hline \multicolumn{3}{|c|}{ (d) } \\
\hline \multicolumn{3}{|c|}{ Imput Fuction “UPS 1 = UPS 2” } \\
\hline Situation & Off & On \\
\hline Range & $(0300)$ & $(0300)$ \\
\hline Parameters & $(-1200300)$ & (0 300420$)$ \\
\hline \multicolumn{3}{|c|}{$(e-f)$} \\
\hline
\end{tabular}

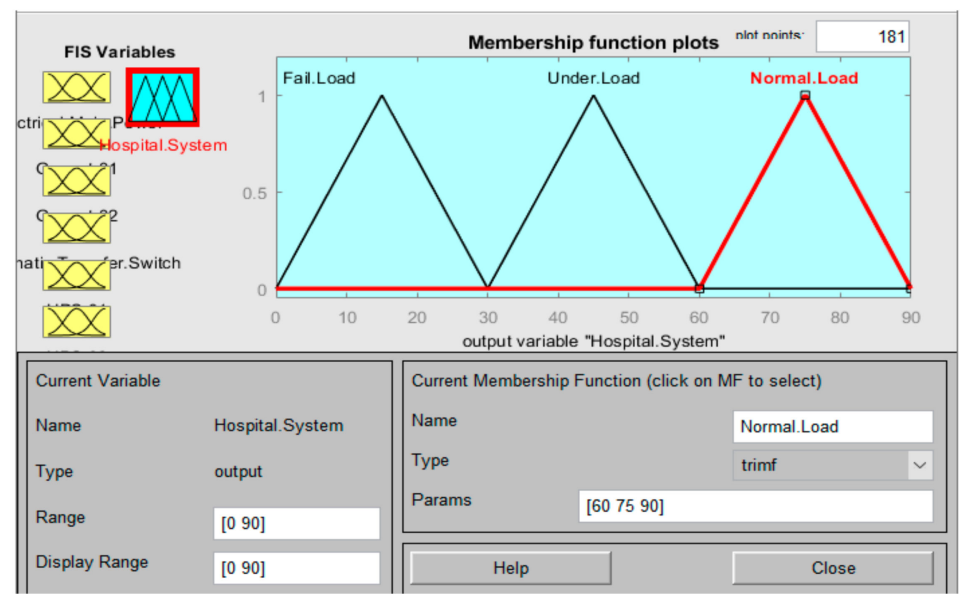

Figure 18. Membership Function Editor output variable "Hospital System".

Table 2. Output function "Hospital System".

\begin{tabular}{cccc}
\hline & \multicolumn{4}{c}{ Output Function “EMP” } & \\
\hline Situation & Fail Load & Under Load & Normal Load \\
\hline Range & $(0$ 90) & $(090)$ & $(090)$ \\
\hline Parameters & $(01530)$ & $(304560)$ & $(607590)$ \\
\hline
\end{tabular}




\subsubsection{Rules of Editor}

The next step is to apply the fuzzy operator "AND \& THEN" in fuzzy rules, and the fuzzy rules that are by data collected and processed according to fuzzy logic with the following 17 rules: (1) If (Electrical Main Power is Low) and (Genset1 is Off) and (Genset2 is Off) and (Automatic Transfer Switch is Not Function) and (UPS1 is Off) and (UPS2 is Off) then (Hospital System is Failing Load); (2) If (Electrical Main Power is Low) and (Genset1 is On) and (Genset2 is Off) and (Automatic Transfer Switch is Function) and (UPS1 is On) and (UPS2 is On) then (Hospital System is Under Load); (3) If (Electrical Main Power is Low) and (Genset1 is Off) and (Genset2 is On) and (Automatic Transfer Switch is Function) and (UPS1 is On) and (UPS2 is On) then (Hospital System is Under Load); (4) If (Electrical Main Power is Low) and (Genset1 is On) and (Genset2 is On) and (Automatic Transfer Switch is Function) and (UPS1 is On) and (UPS2 is Off) then (Hospital System is Under Load); (5) If (Electrical Main Power is Low) and (Genset1 is On) and (Genset2 is On) and (Automatic Transfer Switch is Function) and (UPS1 is Off) and (UPS2 is On) then (Hospital System is Under Load); (6) If (Electrical Main Power is Low) and (Genset1 is On) and (Genset2 is On) and (Automatic Transfer Switch is Not Function) and (UPS1 is On) and (UPS2 is On) then (Hospital System is Under Load); (7) If (Electrical Main Power is Low) and (Genset1 is On) and (Genset2 is On) and (Automatic Transfer Switch is Function) and (UPS1 is On) and (UPS2 is On) then (Hospital System is Normal Load); (8) If (Electrical Main Power is Normal) \& (Genset1 is Off) and (Genset2 is Off) and (Automat-ic Transfer Switch is Not Function) and (UPS1 is Off) and (UPS2 is Off) then (Hospital System is Failing Load); (9) If (Electrical Main Power is Normal) and (Genset1 is Off) and (Genset2 is Off) and (Automatic Transfer Switch is Not Function) and (UPS1 is On) and (UPS2 is On) then (Hospital System is Under Load); (10) If (Electrical Main Power is Normal) and (Genset1 is Off) and (Genset2 is Off) and (Automatic Transfer Switch is Function) and (UPS1 is On) and (UPS2 is On) then (Hospital System is Normal Load); (11) If (Electrical Main Power is High) and (Genset1 is Off) and (Genset2 is Off) and (Automatic Transfer Switch is Not Function) and (UPS1 is Off) and (UPS2 is Off) then (Hospital System is Failing Load); (12) If (Electrical Main Power is High) and (Genset1 is On) and (Genset2 is Off) and (Automatic Transfer Switch is Function) and (UPS1 is On) and (UPS2 is On) then (Hospital System is Under Load); (13) If (Electrical Main Power is High) and (Genset1 is Off) and (Genset2 is On) and (Automatic Transfer Switch is Function) and (UPS1 is On) and (UPS2 is On) then (Hospital System is Under Load); (14) If (Electrical Main Power is High) and (Genset1 is On) and (Genset2 is On) and (Automatic Transfer Switch is Function) and (UPS1 is On) and (UPS2 is Off) then (Hospital System is Under Load); (15) If (Electrical Main Power is High) and (Genset1 is On) and (Genset2 is On) and (Automatic Transfer Switch is Function) and (UPS1 is Off) and (UPS2 is On) then (Hospital System is Under Load); (16) If (Electrical Main Power is High) and (Genset1 is On) and (Genset2 is On) and (Automatic Transfer Switch is Not Function) and (UPS1 is On) and (UPS2 is On) then (Hospital System is Under Load); (17) If (Electrical Main Power is High) and (Genset1 is On) and (Genset2 is On) and (Automatic Transfer Switch is Function) and (UPS1 is On) and (UPS2 is On) then (Hospital System is Normal Load).

To support the fuzzy rules above, it is necessary to sort out the working orders of some important equipment of the electrical power system of the hospital that are being analysed. Based on MATLAB software, the fuzzy inference system was used to simulate how reliable and available their functions are in order to prevent any failure. The support of the fuzzy rules that show the simulation of the referred electrical circuits functioning is shown in Table 3. 
Table 3. Rules editor with numerical values for the fuzzy inference system of electrical systems.

\begin{tabular}{ccccccccc}
\hline \multicolumn{8}{c}{ Rules Editor in Terms of Numerical in the Fuzzy Inference System } \\
\hline \multicolumn{7}{c}{} & \multicolumn{7}{c}{ FIS Membership Fuctions Inputs } & \multicolumn{3}{c}{ FIS Membership Outputs } \\
\hline No. & EMP & Genset 1 & Genset 2 & ATS & UPS 1 & UPS 2 & Hospital System \\
\hline 1 & $\mathbf{0}$ & $\mathbf{0}$ & $\mathbf{0}$ & $\mathbf{0}$ & $\mathbf{0}$ & $\mathbf{0}$ & $\mathbf{1 5}$ & Fail \\
\hline 2 & $\mathbf{0}$ & $\mathbf{1 0 0 0}$ & $\mathbf{0}$ & $\mathbf{2 0 0}$ & $\mathbf{3 0 0}$ & $\mathbf{3 0 0}$ & $\mathbf{4 5}$ & Under Load \\
\hline 3 & $\mathbf{0}$ & $\mathbf{0}$ & $\mathbf{1 0 0 0}$ & $\mathbf{2 0 0}$ & $\mathbf{3 0 0}$ & $\mathbf{3 0 0}$ & $\mathbf{4 5}$ & Under Load \\
\hline 4 & $\mathbf{0}$ & $\mathbf{1 0 0 0}$ & $\mathbf{1 0 0 0}$ & $\mathbf{2 0 0}$ & $\mathbf{3 0 0}$ & $\mathbf{0}$ & $\mathbf{4 5}$ & Under Load \\
\hline 5 & $\mathbf{0}$ & $\mathbf{1 0 0 0}$ & $\mathbf{1 0 0 0}$ & $\mathbf{2 0 0}$ & $\mathbf{0}$ & $\mathbf{3 0 0}$ & $\mathbf{4 5}$ & Under Load \\
\hline 6 & $\mathbf{0}$ & $\mathbf{1 0 0 0}$ & $\mathbf{1 0 0 0}$ & $\mathbf{0}$ & $\mathbf{3 0 0}$ & $\mathbf{3 0 0}$ & $\mathbf{4 5}$ & Under Load \\
\hline 7 & $\mathbf{0}$ & $\mathbf{1 0 0 0}$ & $\mathbf{1 0 0 0}$ & $\mathbf{2 0 0}$ & $\mathbf{3 0 0}$ & $\mathbf{3 0 0}$ & $\mathbf{7 5}$ & Normal Load \\
\hline 8 & $\mathbf{3 6 0}$ & $\mathbf{0}$ & $\mathbf{0}$ & $\mathbf{0}$ & $\mathbf{0}$ & $\mathbf{0}$ & $\mathbf{1 5}$ & Fail \\
\hline 9 & $\mathbf{3 6 0}$ & $\mathbf{0}$ & $\mathbf{0}$ & $\mathbf{0}$ & $\mathbf{3 0 0}$ & $\mathbf{3 0 0}$ & $\mathbf{4 5}$ & Under Load \\
\hline 10 & $\mathbf{3 6 0}$ & $\mathbf{0}$ & $\mathbf{0}$ & $\mathbf{2 0 0}$ & $\mathbf{3 0 0}$ & $\mathbf{3 0 0}$ & $\mathbf{7 5}$ & Normal Load \\
\hline 11 & $\mathbf{6 0 0}$ & $\mathbf{0}$ & $\mathbf{0}$ & $\mathbf{0}$ & $\mathbf{0}$ & $\mathbf{0}$ & $\mathbf{1 5}$ & Fail \\
\hline 12 & $\mathbf{6 0 0}$ & $\mathbf{1 0 0 0}$ & $\mathbf{1 0 0 0}$ & $\mathbf{2 0 0}$ & $\mathbf{3 0 0}$ & $\mathbf{3 0 0}$ & $\mathbf{4 5}$ & Under Load \\
\hline 13 & $\mathbf{6 0 0}$ & $\mathbf{0}$ & $\mathbf{1 0 0 0}$ & $\mathbf{2 0 0}$ & $\mathbf{3 0 0}$ & $\mathbf{3 0 0}$ & $\mathbf{4 5}$ & Under Load \\
\hline 14 & $\mathbf{6 0 0}$ & $\mathbf{1 0 0 0}$ & $\mathbf{1 0 0 0}$ & $\mathbf{2 0 0}$ & $\mathbf{3 0 0}$ & $\mathbf{0}$ & $\mathbf{4 5}$ & Under Load \\
\hline 15 & $\mathbf{6 0 0}$ & $\mathbf{1 0 0 0}$ & $\mathbf{1 0 0 0}$ & $\mathbf{2 0 0}$ & $\mathbf{0}$ & $\mathbf{3 0 0}$ & $\mathbf{4 5}$ & Under Load \\
\hline 16 & $\mathbf{6 0 0}$ & $\mathbf{1 0 0 0}$ & $\mathbf{1 0 0 0}$ & $\mathbf{0}$ & $\mathbf{3 0 0}$ & $\mathbf{3 0 0}$ & $\mathbf{4 5}$ & Under Load \\
\hline 17 & $\mathbf{6 0 0}$ & $\mathbf{1 0 0 0}$ & $\mathbf{1 0 0 0}$ & $\mathbf{2 0 0}$ & $\mathbf{3 0 0}$ & $\mathbf{3 0 0}$ & $\mathbf{7 5}$ & Normal Load \\
\hline & & & & & & & & \\
\end{tabular}

\subsubsection{Rules Viewer}

If (Electrical Main Power is Low) and (Genset1 is off) and (Genset2 is out) and (Automatic Transfer Switch is not function) and (UPS1 is off) and (UPS2 is off) then (Hospital System is failing load)-Figure 19.

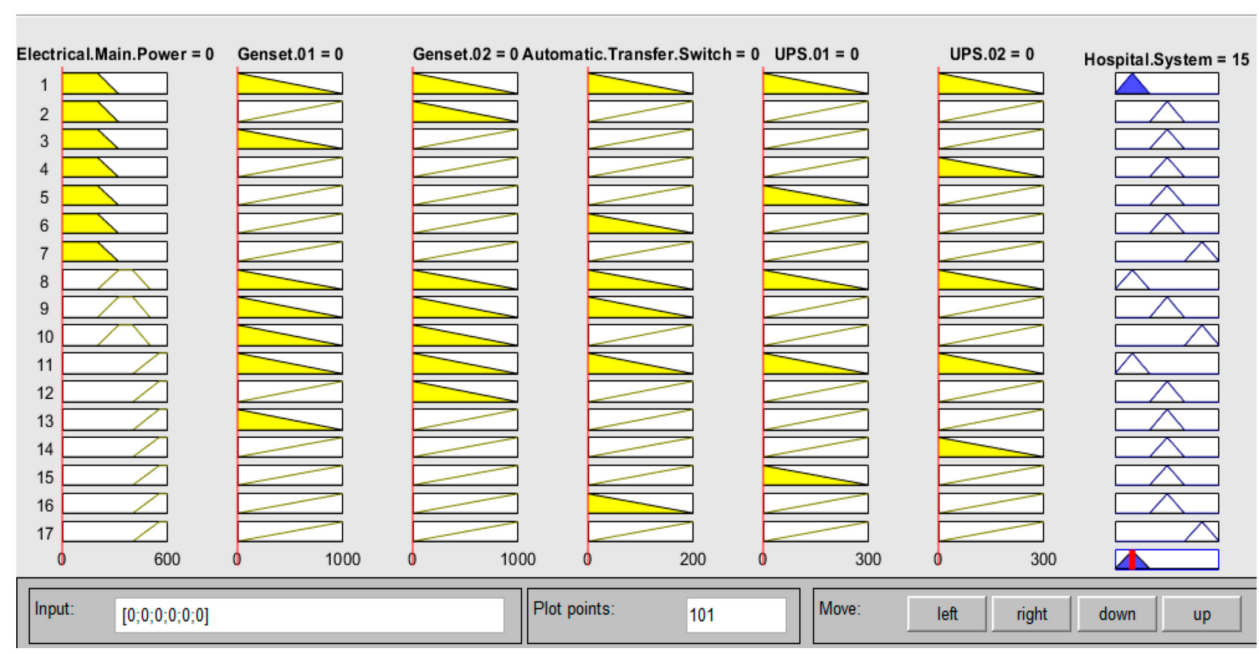

Figure 19. Rules viewer of the fuzzy logic system for Failing Load.

If (Electrical Main Power is Normal) and (Genset1 is off) and (Genset2 is off) and (Automatic Transfer Switch is not function) and (UPS1 is on) and (UPS2 is on) then (Hospital System is under load)-Figure 20.

If (Electrical Main Power is Low) and (Genset1 is On) and (Genset2 is On) and (Automatic Transfer Switch is function) and (UPS1 is On) and (UPS2 is On) then (Hospital System is Normal load)—Figure 21. 


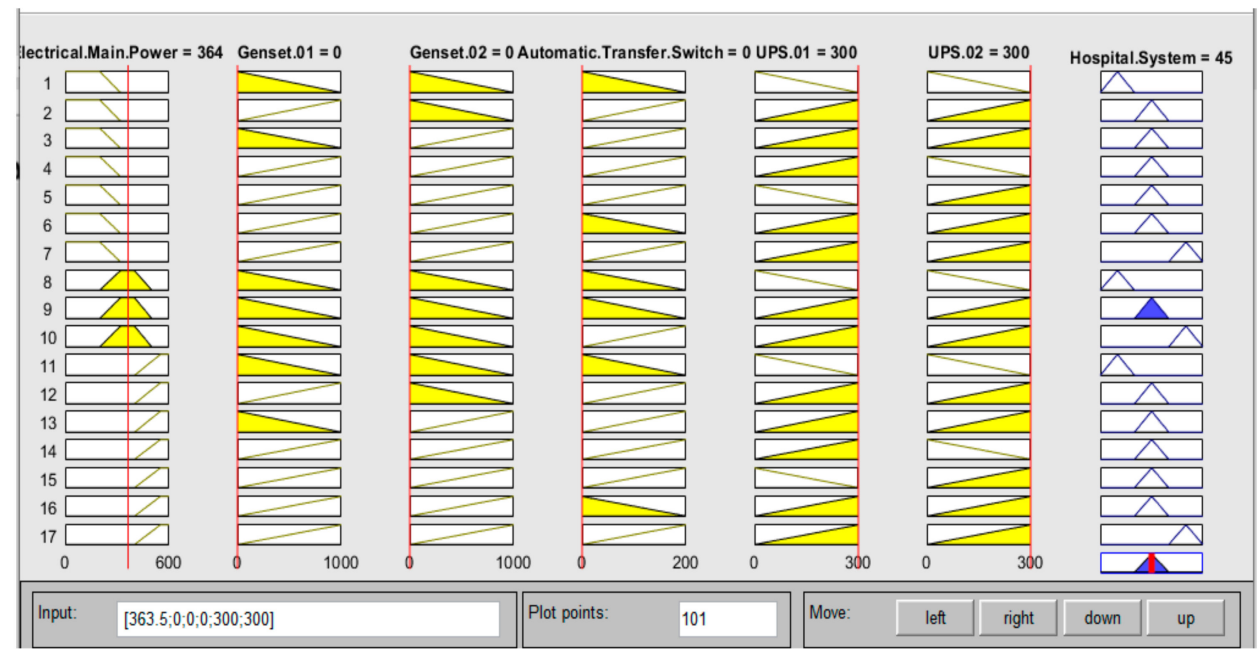

Figure 20. Rules viewer of the fuzzy logic system for Under Load.

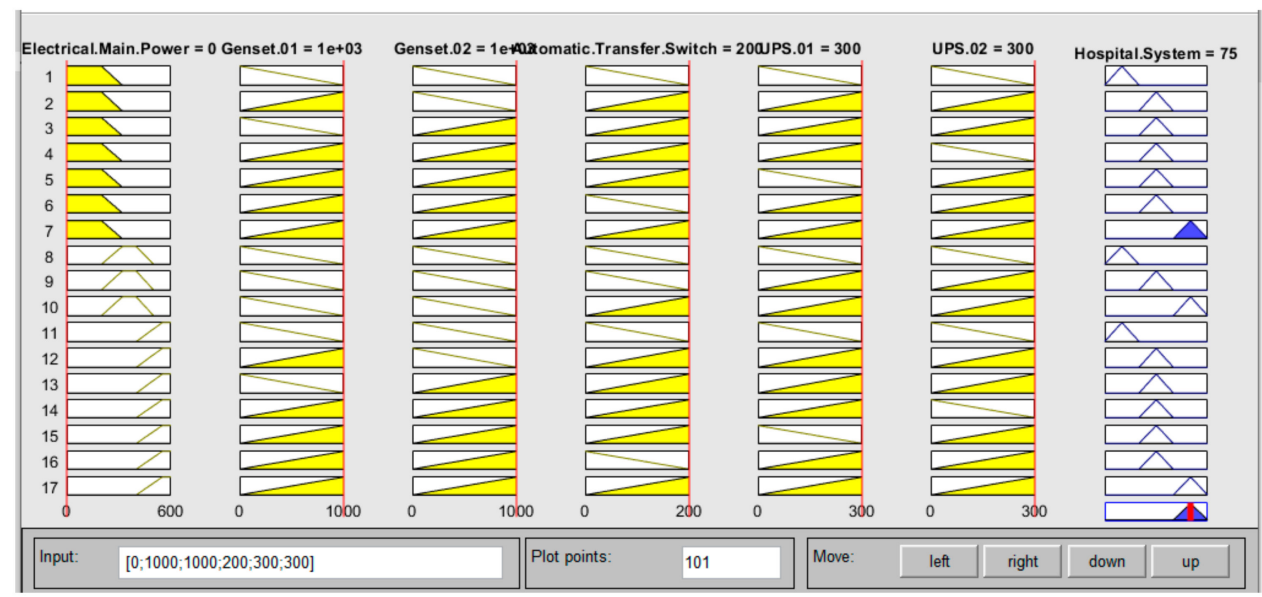

Figure 21. Rules viewer of the fuzzy logic system for Normal Load.

\subsubsection{Surface Viewer}

Fuzzy inference system (FIS) surface viewer for Electrical Main Power (EMP), Genset1 and Genset2, Auto Transfer Switch (ATS), UPS1, and UPS2 is shown in Figure 22a-c.

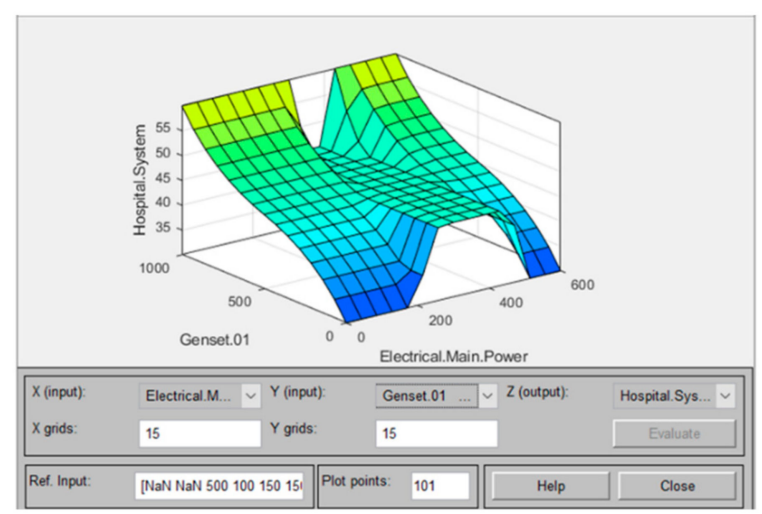

(a)

Figure 22. Cont. 


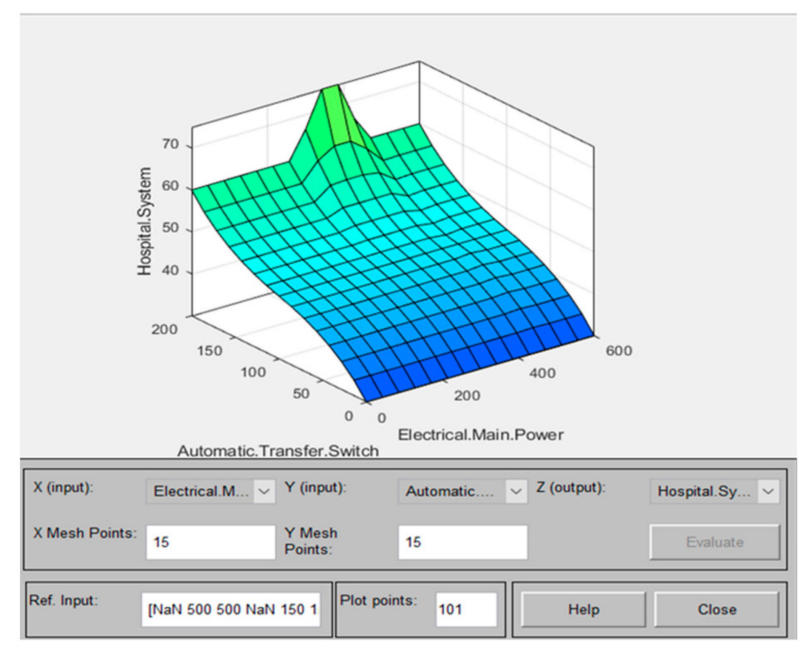

(b)

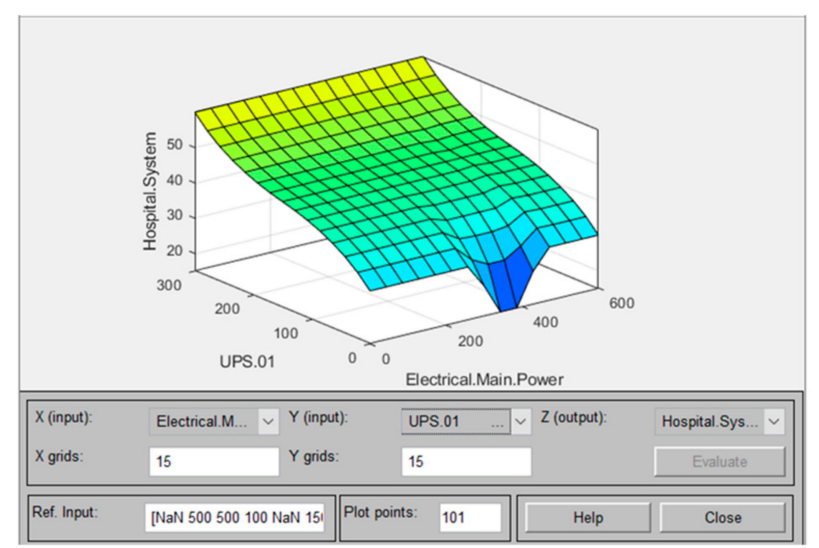

(c)

Figure 22. (a) The surface viewer of the FIS for Electrical Main Power and Genset 01 = Genset 02; (b) Electrical Main Power with ATS; (c) Electrical Main Power with UPS 01 = UPS 02.

\subsection{Synthesis}

The synthesis of the steps shown in previous sections is shown in Figure 23, representing the inference process corresponding to five inputs, 17 rules system, and one output plot.

Based on the description above, the analysis of the electrical power system of a large hospital can be described using Petri nets and a fuzzy inference system based on the following steps: (1) Creating an asset register and numbering system hierarchically; (2) Creating a functional block diagram; (3) Creating a process flow chart; (4) Establishing the system boundary definitions; (5) Creating a Petri net modelling and a fuzzy inference system; and (6) Describing the work function and the operational potential failures.

Based on the steps above, the following results can be obtained that support the actual operational documents in the field: (1) To identify the reliability and the weak points of the system; (2) To redesign the system aiming to remove the weakest points of the system to guarantee the asset reliability; (3) To simulate the most important solutions to improve the system reliability; and (4) To choose the best solution for the desired system reliability. 


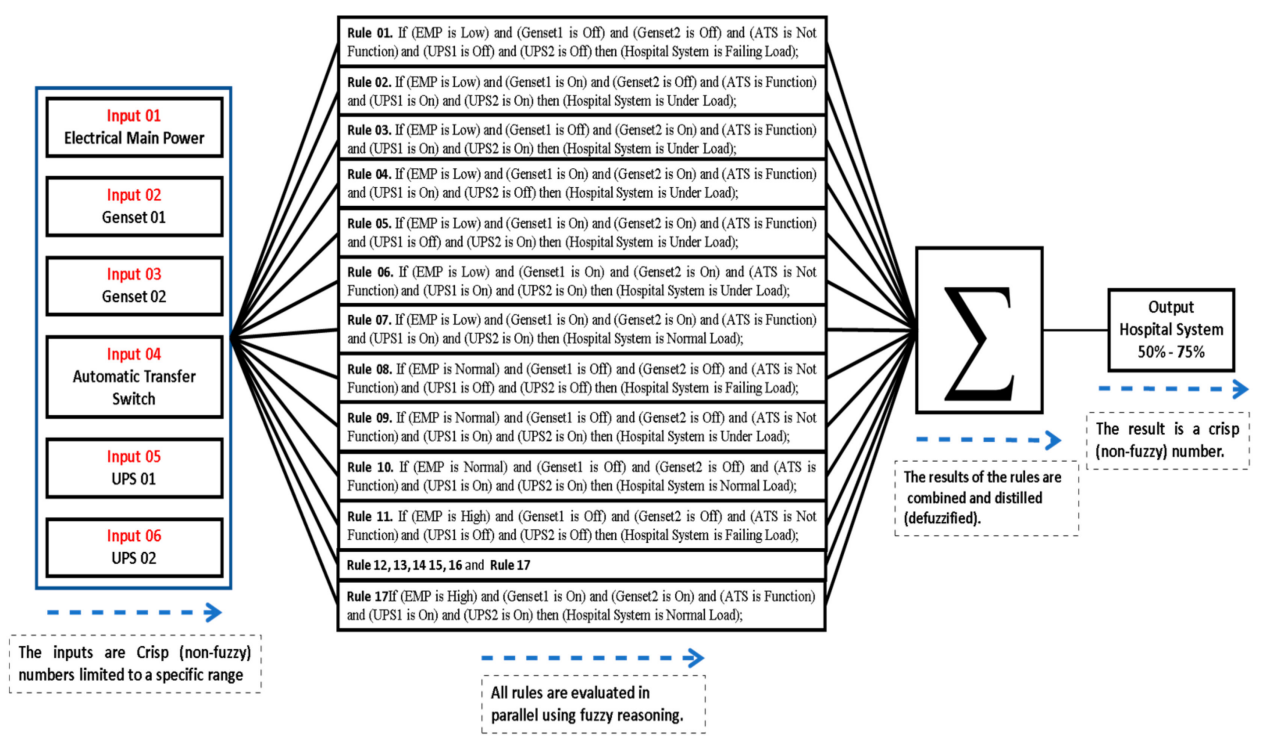

Figure 23. The surface viewer of the fuzzy logic system for the cycle of the process.

\section{Conclusions}

The paper demonstrates the usefulness and relevance of Petri nets in the dynamic modelling and analysing of the hospital's electrical power supply systems. The paper demonstrates how Petri nets can help to identify the weaknesses in a complex electrical system, to simulate more reliable solutions, and to validate them. With Petri nets, it is possible to identify the most critical components of the electrical system in a hospital. As there is no historical maintenance available, the authors used the fuzzy inference system to analyse the system with excellent results, as shown in the paper. The paper emphasizes the Petri nets and fuzzy inference system as a powerful tool to support maintenance management, providing the analysis and simulation approach for this type of system aiming to increase their reliability and availability. Based on the simulations of Petri nets, it is possible to identify the most critical devices in the electrical energy system of a large European hospital. The case study used a fuzzy inference system that demonstrates that the function of the assets, on average, reaches only $45 \%$ of reliability and availability since the function of the assets in their usefulness is only between $50 \%$ to $75 \%$. To solve this weakness, the authors propose to install redundant automatic transfer switches (ATSs) to increase the asset's reliability and availability. Based on the preceding, it can be stated the contribution of the approach carried out along the paper, based on Petri nets and fuzzy logic to identify the reliability weak points in electrical power systems and to evaluate the new performance after the improvements are done in order to reach the desired availability. Still, the approach done can be generalized to any other organization, regardless of its nature.

The future developments to be carried on will be based on the comparison between the approach done in the present paper and a stochastic one, namely when it is used as a Reliability Centred Maintenance policy.

Author Contributions: Main research was done by C.A.P.; J.T.F. is the Supervisor; S.S. and H.R. contributed through their critical analysis about the methodology and results. All authors have read and agreed to the published version of the manuscript.

Funding: This research is sponsored by FEDER funds through the program COMPETE-Programa Operacional Factores de Competitividade—and by national funds through FCT—Fundação para a Ciência e a Tecnologia - under the project UIDB/00285/2020.

Institutional Review Board Statement: Not applicable.

Informed Consent Statement: Not applicable.

Data Availability Statement: Data is contained within the article. 
Conflicts of Interest: The authors declare no conflict of interest.

\section{References}

1. American Hospital Association (AHA). Hospital Engineering Handbook; American Hospital Association: Chicago, IL, USA, 1980; ISBN 0-939450-74-7.

2. Anderson Ronald, T.; Lewis, N. Reliability Centred Maintenance Management and Engineering Methods; Elsevier Science Publishing Co., Inc: New York, NY, USA, 1990; ISBN 1-85166-470-X.

3. Department of the Army. TM 5-698-2 Reliability-Centred Maintenance (RCM) for Command, Control, Communications, Computer, Intelligence, Surveillance, and Reconnaissance (C4ISR) Facilities; Headquarters Department of the Army: Washington, DC, USA, 2003; Available online: https://www.wbdg.org/FFC/ARMYCOE/COETM/tm_5_698_2.pdf (accessed on 27 December 2015).

4. Farinha, J. Manutenção A Terologia e as Novas Ferramentas de Gestão; Edição, Monitor, Lda: Lisboa, Portugal, 2011 ; ISBN 9789729413827.

5. Gulati, R.; Smith, R. Maintenance and Reliability Best Practices; Industrial Press: New York, NY, USA, 2009; ISBN 978-0-8311-3311-5.

6. Moubray, J. Reliability-Centred Maintenance; Industrial Press: New York, NY, USA, 1997; ISBN 0-8311-3078-4.

7. Wang, W. An overview of the recent advances in delay-time-based maintenance modelling. Reliab. Eng. Syst. Saf. 2012, 106, 165-178. [CrossRef]

8. Mwanza, B.G.; Mbohwa, C. An Assessment of the Effectiveness of Equipment Maintenance Practices in Public Hospitals. Procedia Manuf. 2015, 4, 307-314. [CrossRef]

9. The "IEEE C2: National Electrical Safety Code, 2007"; The Instituto of Electrical and Electronics Engineering: New York, NY, USA, 2007; ISBN 0-7381-4893-8.

10. Christiansen, N.; Kaltschmitt, M.; Dzukowski, F.; Isensee, F. Electricity consumption of medical plug loads in hospital laboratories: Identification, evaluation, prediction and verification. Energy Build. 2015, 107, 392-406. [CrossRef]

11. BenSaleh, M.S.; Hermache, A.S. Planning, optimizing and analyzing of safety and maintenance for the critical role of emergency power plant in saudi healthcare facilities. In Proceedings of the 2010 IEEE Region 8 International Conference on Computational Technologies in Electrical and Electronics Engineering (SIBIRCON), Irkutsk, Russia, 11-15 July 2010. [CrossRef]

12. Jamshidi, A.; Rahimi, S.A.; Ait-Kadi, D.; Ruiz, A. A comprehensive fuzzy risk-based maintenance framework for prioritization of medical devices. Appl. Soft Comput. 2015, 32, 322-334. [CrossRef]

13. The WHO (World Health Organization and Pan American Health Organization); World Health Organization: Geneva, Switzerland, 2015; ISBN 978-92-4-154898-4.

14. Hameed, A.; Khan, F.; Ahmed, S. A risk-based shutdown inspection and maintenance interval estimation considering human error. Process. Saf. Environ. Prot. 2016, 100, 9-21. [CrossRef]

15. Ali, W.; Qyyum, M.A.; Khan, M.S.; Duong, P.L.T.; Lee, M. Knowledge-inspired operational reliability for optimal LNG production at the offshore site. Appl. Therm. Eng. 2019, 150, 19-29. [CrossRef]

16. Velásquez, R.M.A.; Lara, J.V.M.; Melgar, A. Reliability model for switchgear failure analysis applied to ageing. Eng. Fail. Anal. 2019, 101, 36-60. [CrossRef]

17. Calixto, E. Reliability, Availability, and Maintainability (RAM Analysis). In Gas and Oil Reliability Engineering; Elsevier: Amsterdam, The Netherlands, 2016; pp. 269-470. [CrossRef]

18. Çekyay, B.; Özekici, S. Reliability, MTTF and steady-state availability analysis of systems with exponential lifetimes. Appl. Math. Model. 2015, 39, 284-296. [CrossRef]

19. Corvaro, F.; Giacchetta, G.; Marchetti, B.; Recanati, M. Reliability, Availability, Maintainability (RAM) study, on reciprocating compressors API 618. Petroleum 2017, 3, 266-272. [CrossRef]

20. Ebeling, C. An Introduction to Reliability and Maintainability Engineering; Waveland Press: Long Grove, IL, USA, 2010.

21. Feng, Q.; Zhu, C.; Sun, B.; Liu, L. Process reengineering method for synthesis design of reliability maintainability supportability and performance. In Proceedings of the 2011 9th International Conference on Reliability, Maintainability, and Safety, Guiyang, China, 12-15 June 2011. [CrossRef]

22. Hameed, Z.; Vatn, J.; Heggset, J. Challenges in the reliability and maintainability data collection for offshore wind turbines. Renew. Energy 2011, 36, 2154-2165. [CrossRef]

23. Sikos, L.; Klemeš, J. Reliability, availability and maintenance optimisation of heat exchanger networks. Appl. Therm. Eng. 2010, 30, 63-69. [CrossRef]

24. Song, Y.; Wang, B. Survey on Reliability of Power Electronic Systems. IEEE Trans. Power Electron. 2013, 28, 591-604. [CrossRef]

25. Sutton, I. Reliability, Availability, and Maintainability. In Process Risk and Reliability Management; Elsevier: Amsterdam, The Netherlands, 2015; pp. 667-688. [CrossRef]

26. Wang, J.-J.; Fu, C.; Yang, K.; Zhang, X.-T.; Shi, G.-H.; Zhai, J. Reliability and availability analysis of redundant BCHP (building cooling, heating and power) system. Energy 2013, 61, 531-540. [CrossRef]

27. Zio, E.; Fan, M.; Zeng, Z.; Kang, R. Application of reliability technologies in civil aviation: Lessons learnt and perspectives. Chin. J. Aeronaut. 2019, 32, 143-158. [CrossRef]

28. Shen, J.; Cui, L.; Ma, Y. Availability and optimal maintenance policy for systems degrading in dynamic environments. Eur. J. Oper. Res. 2019, 276, 133-143. [CrossRef]

29. Do, P.; Vu, H.C.; Barros, A.; Bérenguer, C. Maintenance grouping for multi-component systems with availability constraints and limited maintenance teams. Reliab. Eng. Syst. Saf. 2015, 142, 56-67. [CrossRef] 
30. Pinto, C.A.; Farinha, J.T.; Singh, S. Contributions of Petri Nets to the Reliability and Availability of an Electrical Power System in a Big European Hospital-A Case Study. WSEAS Trans. Syst. Control. 2021, 16, 21-42. [CrossRef]

31. Wang, J. Timed Petri Nets: Theory and Application; Springer US: Boston, MA, USA, 1998; ISBN 978-1-4615-5537-7.

32. Volovoi, V. Modeling of system reliability Petri nets with aging tokens. Reliab. Eng. Syst. Saf. 2004, 84, 149-161. [CrossRef]

33. Chew, S.; Dunnett, S.; Andrews, J. Phased mission modelling of systems with maintenance-free operating periods using simulated Petri nets. Reliab. Eng. Syst. Saf. 2008, 93, 980-994. [CrossRef]

34. Garg, H. Reliability analysis of repairable systems using Petri nets and vague Lambda-Tau methodology. ISA Trans. 2013, 52, 6-18. [CrossRef] [PubMed]

35. Leigh, J.M.; Dunnett, S.J. Use of Petri Nets to Model the Maintenance of Wind Turbines. Qual. Reliab. Eng. Int. 2014, 32, 167-180. [CrossRef]

36. Ren, Z.; Wu, Y. Modeling the Performance of Aircraft Utilizing Maintenance Free Operating Periods. Procedia Eng. 2015, 99, 214-218. [CrossRef]

37. Sadou, N.; Demmou, H. Reliability analysis of discrete event dynamic systems with Petri nets. Reliab. Eng. Syst. Saf. 2009, 94, 1848-1861. [CrossRef]

38. Eisenberger, D.; Fink, O. Assessment of maintenance strategies for railway vehicles using Petri-nets. Transp. Res. Procedia 2017, 27, 205-214. [CrossRef]

39. Farinha, J. Asset Maintenance Engineering Methodologies; CRC Press/Taylor \& Francis Group: Boca Raton, FL, USA, 2018.

40. Cannarile, F.; Compare, M.; Rossi, E.; Zio, E. A fuzzy expectation maximization based method for estimating the parameters of a multi-state degradation model from imprecise maintenance outcomes. Ann. Nucl. Energy 2017, 110, 739-752. [CrossRef]

41. Ladj, A.; Tayeb, F.B.-S.; Varnier, C.; Dridi, A.A.; Selmane, N. A Hybrid of Variable Neighbor Search and Fuzzy Logic for the permutation flowshop scheduling problem with predictive maintenance. Procedia Comput. Sci. 2017, 112, 663-672. [CrossRef]

42. Touat, M.; Bouzidi-Hassini, S.; Benbouzid-Sitayeb, F.; Benhamou, B. A hybridization of genetic algorithms and fuzzy logic for the single-machine scheduling with flexible maintenance problem under human resource constraints. Appl. Soft Comput. 2017, 59, 556-573. [CrossRef]

43. Jaderi, F.; Ibrahim, Z.Z.; Zahiri, M.R. Criticality analysis of petrochemical assets using risk based maintenance and the fuzzy inference system. Process. Saf. Environ. Prot. 2019, 121, 312-325. [CrossRef]

44. Ratnayake, R.C.; Antosz, K. Development of a Risk Matrix and Extending the Risk-based Maintenance Analysis with Fuzzy Logic. Procedia Eng. 2017, 182, 602-610. [CrossRef]

45. Seiti, H.; Hafezalkotob, A.; Fattahi, R. Extending a pessimistic-optimistic fuzzy information axiom based approach considering acceptable risk: Application in the selection of maintenance strategy. Appl. Soft Comput. 2018, 67, 895-909. [CrossRef]

46. Babashamsi, P.; Golzadfar, A.; Yusoff, N.I.M.; Ceylan, H.; Nor, N.G.M. Integrated fuzzy analytic hierarchy process and VIKOR method in the prioritization of pavement maintenance activities. Int. J. Pavement Res. Technol. 2016, 9, 112-120. [CrossRef]

47. Cordón, O. A historical review of evolutionary learning methods for Mamdani-type fuzzy rule-based systems: Designing interpretable genetic fuzzy systems. Int. J. Approx. Reason. 2011, 52, 894-913. [CrossRef]

48. Zahabi, M.; Kaber, D. A fuzzy system hazard analysis approach for human-in-the-loop systems. Saf. Sci. 2019, $120,922-931$. [CrossRef]

49. Akgun, A.; Sezer, E.; Nefeslioglu, H.; Gokceoglu, C.; Pradhan, B. An easy-to-use MATLAB program (MamLand) for the assessment of landslide susceptibility using a Mamdani fuzzy algorithm. Comput. Geosci. 2012, 38, 23-34. [CrossRef]

50. Kacimi, M.A.; Guenounou, O.; Brikh, L.; Yahiaoui, F.; Hadid, N. New mixed-coding PSO algorithm for a self-adaptive and automatic learning of Mamdani fuzzy rules. Eng. Appl. Artif. Intell. 2020, 89, 103417. [CrossRef]

51. Lu, K.-Y.; Sy, C.-C. A real-time decision-making of maintenance using fuzzy agent. Expert Syst. Appl. 2009, 36, 2691-2698. [CrossRef]

52. Dhimish, M.; Holmes, V.; Mehrdadi, B.; Dales, M. Comparing Mamdani Sugeno fuzzy logic and RBF ANN network for PV fault detection. Renew. Energy 2018, 117, 257-274. [CrossRef]

53. Kraidi, L.; Shah, R.; Matipa, W.; Borthwick, F. Using stakeholders' judgement and fuzzy logic theory to analyze the risk influencing factors in oil and gas pipeline projects: Case study in Iraq, Stage II. Int. J. Crit. Infrastruct. Prot. 2020, 28, 100337. [CrossRef]

54. Khosravanian, R.; Sabah, M.; Wood, D.A.; Shahryari, A. Weight on drill bit prediction models: Sugeno-type and Mamdani-type fuzzy inference systems compared. J. Nat. Gas Sci. Eng. 2016, 36, 280-297. [CrossRef]

55. Teo, T.T.; Logenthiran, T.; Woo, W.L.; Abidi, K.; John, T.; Wade, N.S.; Greenwood, D.M.; Patsios, C.; Taylor, P.C. Optimization of Fuzzy Energy-Management System for Grid-Connected Microgrid Using NSGA-II. IEEE Trans. Cybern. 2020, 1-12. [CrossRef]

56. Teo, T.T.; Thillainathan, L.; Woo, W.L.; Abidi, K. Intelligent Controller for Energy Storage System in Grid-Connected Microgrid. IEEE Trans. Syst. Man Cybern. Syst. 2021, 51, 650-658. [CrossRef]

57. Teo, T.T.; Logenthiran, T.; Woo, W.L.; Abidi, K. Fuzzy logic control of energy storage system in microgrid operation. In Proceedings of the 2016 IEEE Innovative Smart Grid Technologies-Asia (ISGT-Asia), Melbourne, VIC, Australia, 28 November-1 December 2016; pp. 65-70.

58. HiPS: Hierarchical Petri Net Simulator. Available online: http://sourceforge.net/projects/hips-tools/ (accessed on 27 December 2015). 